Article

\title{
Success or Waste of Taxpayer Money? Impact Assessment of Rural Development Programs in Hungary
}

\author{
Zoltán Bakucs ${ }^{1,2, * \mathbb{C}}$, Imre Fertó ${ }^{1,3}$ and Zsófia Benedek ${ }^{1}$ \\ 1 Centre for Economic and Regional Studies, Hungarian Academy of Sciences, Budapest H-1097, Hungary; \\ imre.ferto@krtk.mta.hu (I.F.); zsofia.benedek@krtk.mta.hu (Z.B.) \\ 2 Corvinus University of Budapest, Budapest H-1093, Hungary \\ 3 Kaposvár University, Kaposvár H-7400, Hungary \\ * Correspondence: zoltan.bakucs@krtk.mta.hu
}

Received: 8 March 2019; Accepted: 5 April 2019; Published: 11 April 2019

\begin{abstract}
The effectiveness of support directed to less developed regions is a timely question more than halfway through the 2014-2020 programming period. We present an analysis of the impact of rural development support on the well-being of Hungarian LAU1 regions between 2008 and 2013. The aim was to measure the overall impact of all of the Rural Development Funds, covering all measures within the program. Two indices of local well-being were used: the multi-dimensional, local-variables-based Regional Development Index that measures the overall level of regional development and a simple, migration-based index as a proxy for perceived quality of life. Generalized propensity score matching, and difference-in-differences estimation techniques were employed to evaluate the impact of subsidies. Irrespective of how the amount of support was calculated, the measure of local well-being, or the methodology employed, the impact was not significant, and was sometimes even negative. This casts doubt on the effectiveness of Rural Development Policy in Hungary.
\end{abstract}

Keywords: Rural Development Policy; impact assessment; LAU1 regions; generalized propensity score matching; difference in differences

\section{Introduction}

After agricultural transfers, the second largest share of European Union's (EU) budget is dedicated to the funding of the Regional Policy. With a share of $40 \%$ of EU budget, Regional Policy aims for sustainable local development of EU regions. For this purpose, 347 billion Euros were spent in the 2007-2013 programming period and 347 billion euros are foreseen for the 2014-2020 programming period. Several funds are used for this purpose. European Regional Development Fund "aims to strengthen economic and social cohesion in the European Union by correcting imbalances between its regions" (https://ec.europa.eu/regional_policy/en/funding/), focusing on investments into research and innovation, support for small- and medium-sized enterprises, the digital agenda and the low-carbon economy. The Cohesion Fund supports large infrastructural investments such as energy and transport investments that benefit the environment in Bulgaria, Croatia, Cyprus, the Czech Republic, Estonia, Greece, Hungary, Latvia, Lithuania, Malta, Poland, Portugal, Romania, Slovakia and Slovenia, i.e., in Member States where Gross National Income per capita is less than $90 \%$ of the EU average. The European Social Fund "invests in people, with a focus on improving employment and education opportunities across the European Union. It also aims to improve the situation of the most vulnerable people at risk of poverty" (https:/ / ec.europa.eu/regional_policy/en/funding/). 
In the 2007-2013 programming period, Hungary received some 25 billion euros from these funds. Relatively small compared to these interventions, the European Agricultural Fund for Rural Development provides the means of Rural Development Policy. Within the EU, Hungary is one of the biggest beneficiaries of Rural Development Program (RDP) payments-at least as far as per-capita transfers are considered. In the 2007-2013 programming period, EUR 3.8 billion was spent, while, in the 2014-2020 period, EUR 4.2 billion (of which EUR 740 million in the form of national co-funding) is earmarked for this purpose. The question that naturally arises is: Do these substantial transfers make a difference? The European Commission's mandatory ex-ante, mid-term and ex-post program evaluations-based on the monitoring of a set of (partial) indicators and qualitative assessment-fail to provide an answer because of the need for uniformity and comparability across Member States.

Papers generally focus on the impact of Structural Funds, more precisely on the impact of Objective 1 programs (Objective 1 programs are the largest measure within the EU cohesion policy, targeting regions with GDP (evaluated at Purchasing Power) less than $75 \%$ of the EU average) upon European regions. Several strands of literature may be identified. The first one analyzes to which extent the main goal of the Regional Policy, i.e., the convergence of European regions was achieved [1-3]. A second group of papers focus on the impact of structural funds on the economic-most often GDP per capita-growth [2,4-9], or employment growth [4,5,10] of regions. Reference [11] focused on the impact of Cohesion Policy on the economic performance of the most disadvantaged regions (NUTS3 level), while the effect of European Structural and Investment Fund payments on the performance of local governments in Portugal were assessed by Caldas et al. [12]. Further, [13] analyzed the impact of Cohesion Policy on regional productivity growth, and [14] examined the territorial impacts of EU development policy. The work of Michalek and Zarnekow [15] is the only paper to describe the Central and Easter European space from this perspective.

Some academics use firm level data for impact evaluation. Thus, [16] quantified the impact of Rural Development subsidies upon the productivity, profitability and efficiency of Czech meat processing industry, $[17,18]$ analyzed the effect of innovation subsidies in Sweden and East German territories, respectively, [19] analyzed a unique firm level dataset of 2 million projects funded by structural and cohesion funds over the 2007-2013 period for EU 25 countries, and [20] employed meta-regression to analyze the results of 17 papers providing 323 estimates on the impact of Structural Funds upon growth.

Note, there is a lack of papers focusing on RDP rather than impact of Structural and Cohesion Funds. Policy evaluation or impact assessment of RDP is a rather complicated issue since such complex notions are hard to quantify, while all relevant components of the impact should be captured in a transparent and easy-to-handle fashion. Two notable issues add complexity to any impact analysis. First, the use of partial indicators such as increases in local GDP levels, decreases in unemployment rate, the value of program-generated investment, and the number of programs (or area) supported (see, e.g., [15] for a detailed discussion). Moreover, GDP data are not available at a disaggregated level, thus analysts are constrained by a lack of data concerning potential indicators. The second issue is the problem of constructing the appropriate counterfactual situation for impact analysis. More exactly, program impact evaluation cannot correctly be undertaken unless the impact is measured by comparing actual and counterfactual outcomes. However, the counterfactual situation may not be observed. Thus, the main challenge of impact analysis is to construct a convincing and reasonable comparison group (counterfactual) for beneficiaries in the absence of data. The very recent paper by Castaño et al. [21] explores in detail the use of counterfactuals in the ex-post evaluation of 2007-2013 RDP. Using the example of seven evaluations employing rather different empirical methodologies, the authors highlighted the difficulties with respect to data needs and limiting methodological assumptions. They did, however, "recommend the use of advanced counterfactual approaches to provide evidence of programme impacts". The often-employed naïve approaches to the impact evaluation of RDP (case studies or partial-indicator-based approaches) completely neglect this second issue [22]. The most important weakness of partial indicators is that they may not be treated as exogenous to 
levels of development. It follows that, in these analyses, there is no clear unidirectional causality between RDP and local development. The use of a complex Rural Development Indicator (RDI), as originally proposed by Michalek and Zarnekow [15] and later employed in the Hungarian context by Bakucs et al. [23], combined with propensity score matching methodology, allows the creation of a counterfactual and thus solves problems with endogeneity.

In this study, we followed this approach and constructed a synthetic development index, complemented by an internal-migration-based index, assuming that, regardless of computed local development scores, people tend to migrate to areas where perceived quality of life is higher. In contrast to [24], who investigated only the impact of the SAPARD programs in Poland and in Slovakia between 2002 and 2005, we focused on the 2008-2013 period and cover all rural development policy measures. We addressed the following simple question: Has the significant amount of Rural Development funds that have been distributed had any measurable impact? We went beyond estimating the causal effects of RDP and the use of a simple binary treatment indicator by estimating propensity score matching difference-in-differences (PSM-DID) models and using parametric and semiparametric generalized propensity score matching approaches (GPS). Estimating a dose-response function in the framework of GPS provides more information regarding the effectiveness of a program by uncovering heterogeneities in the effects of RDP at different treatment levels. In doing this, we built on recent advances in the applied econometrics of impact evaluation, as well as recent empirical studies using GPS. For example, highly disaggregated (firm-level) data was used by Bia and Mattei [25] to evaluate the effect of financial support allocated to Piedmont enterprises upon employment growth, while [26] analyzed the impact of product innovation intensity upon European companies-both approaches employ generalized propensity score matching. Closer to the present topic is research by Michalek and Ciaian [27], who used generalized propensity score methods to evaluate the capitalization of farm single payments into the land value in the EU and the research of Esposti [28], who used generalized propensity score matching to identify and estimate the response of farms to decoupling policy as a treatment effect.

We contribute to the impact assessment literature in several ways. First, in a time when politicians and the general public in Old Member States increasingly question the necessity of transfers towards New Member States, we focused on Hungary, a country with a deteriorating Corruption Perception Index (Hungary's PCI decreased from 55 in 2012 to 48 in 2016 [29]) and mounting evidence of flawed public procurement system along with high ranked corruption [30,31]. Second, by using a territorially disaggregated dataset, on Local Administrative Unit (LAU1) level, we had sufficient observations to analyze the impact of RDP in a single country context, minimizing the heterogeneity of unobservable variables thus increasing the validity of counterfactual ([10]). Third, we used a spatial spillover panel model to derive the synthetic Rural Development Indicator, thus we avoided the potential bias due to unaccounted spatial variables. Finally, in line with the most recent literature, after estimating PSM-DID models, we shifted from the binary definition of treatment and use Generalized Propensity Score matching eliminating the subjective bias of defining treated and non-treated regions.

The rest of the paper is organized as follows. In Section 2, we present the data and a description of the methodological approach. In Section 3, we focus on empirical results. Discussion and some conclusions are provided in the last two sections.

\section{Materials and Methods}

Hungary, a Central-European Country, acceded to the European Union in 2004. It covers an area of $93,000 \mathrm{~km}^{2}$ with an approximate population of 9.8 million. At NUTS (Nomenclature des Unités Territoriales Statistiques-nomenclature of territorial units for statistics) 1 level, there are three, at NUTS 2 six, and at NUTS 3 twenty regions (nineteen counties plus the capital city, Budapest). At the Local Administrative Unit level (LAU1, formerly NUTS4), there are 174 small regions composed of 3164 administratively independent settlements. We employed a highly disaggregated dataset of yearly data with respect to these administratively independent settlements, which we believe contributes to the unique nature of this research. The T-STAR database of the Hungarian Central Statistical Office 
was obtained from the CERS-HAS databank (http://adatbank.krtk.mta.hu/adatbazisok_tstar). The related data are designed for use in spatial studies and consist of several hundred variables relating to demographics, public health, education, pollution, unemployment, social care, economic entities, infrastructure, commerce and hospitality, tourism, culture, housing stock, municipal aid, municipal budgets, agriculture and personal income tax. These variables are available for the 2007-2013 period for all 3164 administratively independent Hungarian settlements. An internal migration database was provided by the Hungarian Central Statistical Office. Data about development funds for the period 2008-2013 were taken from the Information Systems of National Regional Development. Using total payments per locality, we created three support indicators: total subsidy, subsidy per $\mathrm{km}^{2}$, and subsidy per capita in LAU1 regions. The descriptive statistics for the development subsidies (years 2008-2013, total per region, per capita and per square $\mathrm{km}$ ) presented in Table 1 emphasize the uneven distribution of funds.

Table 1. Descriptive statistics for subsidies for the period 2008-2013.

\begin{tabular}{cccccc}
\hline Variable & Obs. & Mean & Std. Dev. & Min. & Max. \\
\hline T. subsidy (k. HUF *) & 1044 & $780,185.1$ & $814,366.4$ & $-36,435$ & $7,111,930$ \\
Subsidy/cap (k. HUF) & 1044 & 19.707 & 17.077 & -2.106 & 126.25 \\
Subsidy $/ \mathrm{km}^{2}(\mathrm{k} . \mathrm{HUF})$ & 1044 & 1386.61 & 1209.213 & -95.581 & $13,203.6$ \\
\hline
\end{tabular}

Source: Own calculations. ${ }^{*}$ EUR 1 = HUF 315 (as of 8 March 2019).

The average value of support per LAU1 region amounted to HUF 780 Million, but there were regions with very low levels of support, while in some regions the maximum value of support reached HUF 7.1 billion. This uneven distribution is also reflected in the extremely high standard deviations. The negative minimum numbers in the table are due to two regions that had to repay RDP funds. The picture is made more nuanced by the last two rows in Table 1 (per capita and per square km subsidy), in which the inequality of distribution is less prominent. [23] found an increase in the concentration of subsidies awarded between 2002 and 2008. Figure 1 suggests that the concentration of subsidies further increased in the period under examination.

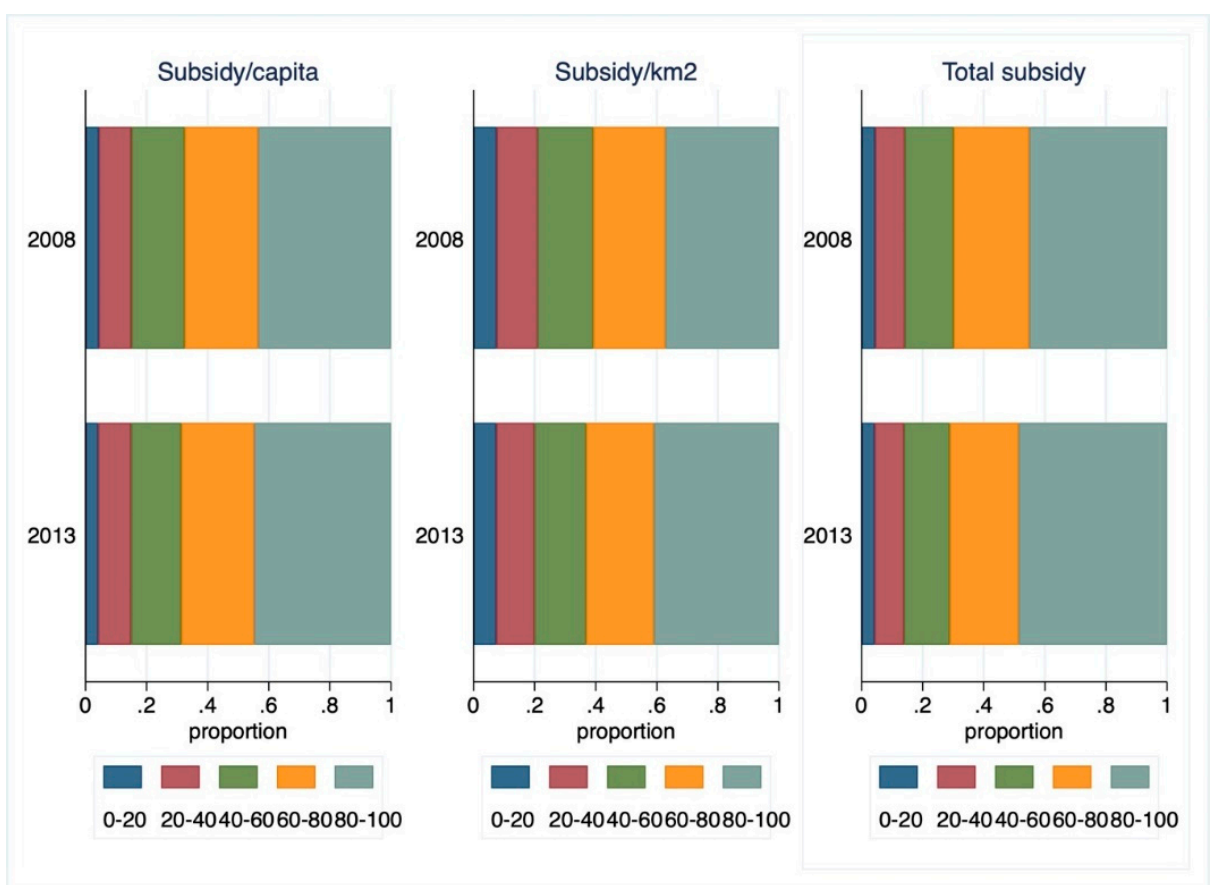

Figure 1. Distribution of subsidies (2008 and 2013). Source: Own calculations. 
This concentration was more prominent for total subsidy and subsidy per capita, and somewhat less for subsidy per $\mathrm{km}^{2}$. Figure A1 in Appendix A depicts the box plot graphs of total, per capita and per $\mathrm{km}^{2}$ subsidies; here, we focus on the yearly average and median values of all subsidy variables (Table 2).

Table 2. Yearly average and median value of subsidy variables (2008-2013).

\begin{tabular}{|c|c|c|c|c|c|c|}
\hline \multirow[t]{2}{*}{ Year } & \multicolumn{2}{|c|}{ T. Subsidy (k. HUF *) } & \multicolumn{2}{|c|}{ Subsidy/cap (k. HUF) } & \multicolumn{2}{|c|}{ Subsidy $/ \mathrm{km}^{2}$ (k. HUF) } \\
\hline & Mean & Median & Mean & Median & Mean & Median \\
\hline 2008 & $415,932.6$ & $329,751.3$ & 10.42 & 8.95 & 7.41 & 6.64 \\
\hline 2009 & $896,959.9$ & $675,489.2$ & 21.80 & 19.17 & 15.82 & 14.40 \\
\hline 2010 & 344,438 & $278,852.4$ & 8.80 & 7.10 & 6.11 & 5.43 \\
\hline 2011 & $916,278.1$ & $649,107.1$ & 23.28 & 18.96 & 16.32 & 13.79 \\
\hline 2012 & $1,010,492$ & $768,804.1$ & 25.75 & 22.18 & 18.05 & 16.68 \\
\hline 2013 & $1,097,327$ & $843,807.7$ & 28.20 & 22.90 & 19.47 & 16.59 \\
\hline
\end{tabular}

The interesting numbers are the average subsidies paid in 2009 and 2010. National elections were held in 2010, thus in 2009 the distribution of payments was sped up (see the doubled mean and median values) by the government-which ultimately lost the election. The newly elected Government in 2010 completely reorganized the system and agency of payments, thus the means of subsidy variables for 2010 were almost three times lower than those of earlier years.

Our empirical strategy consisted of three steps. First, we calculated the region- and year-specific net migration rate variable as a proxy indicator for quality of life in a given region (Equation (1)):

$$
\text { NMR }=(\text { inmigr-outmigr }) / \text { pop }
$$

where inmigr is the inflow of people into a LAU1 region, outmigr is the outflow and pop is the local population. Since the seminal article of [32], the "voting by foot" theory has often been used to proxy the perceived quality of life in a region. In its simplest way it states that people move to locations where they are better off, and thus analyzing regional migration rates may approximate local development levels ([33-35] or more recently [36,37]).

Second, we composed a local, composite development indicator based on the wealth of variables available in the T-STAR database. There are several potential approaches to this. One common approach is to manually select variables of importance and use various weighting schemes to compose the indicator. Obviously, this approach is highly subjective and the weighting formula is often questionable at best. The most often used methods, however, involve factor/principal component analysis (i.e., "let the data choose") and the construction of indicators based on selected variables. Factor and Principal Component Analysis was used by Michalek and Zarnekow [15] to evaluate the SAPARD program in Poland and Slovakia. In the Hungarian context, references [38,39] used factor and PCA analysis and employed the same T-STAR dataset as used in this paper to compute regional competitiveness indices. Further, [23] employed similar techniques to derive the dominant factors responsible for regional development levels for the 2002-2008 period. We used all 170 variables expressed as natural units of measurement (number of, quantity of, length of, etc.) that were available for all years and all 3164 administratively independent Hungarian localities. These describe local statistics with respect to demographics, health services, business units, tourism and catering, retail sector, transport and infrastructure, environment, education, culture unemployment, social security, number of dwellings, personal income tax collected, rank (village town, county seat) of the locality, and distance to nearest county seats. The complete list of variables is available upon request. We then summarized local data into 174 LAU1 Hungarian regions and normalized them according to the population of these regions. PCA and factor analysis then followed to reduce the number of 
variables. Data were first tested to determine the applicability of PCA (Kaiser-Meyer-Olkin's measure and Bartlett's test), followed by a rotation algorithm (Varimax). Finally, we used Kaiser selection criteria to retain factors with Eigen values larger than one. The resulting 29 factors could then be used to compose the RDI. A key issue, however, was determining the weight of each factor that was incorporated into the RDI. These weights may be perceived as relative social values attached to each factor, thus the RDI may be biased if equal or other subjectively determined weights are applied. Following the theory presented in [32], later applied by a great number of researchers (e.g., [35,40-42]) and the methodology suggested by Michalek and Zarnekow [15], we used within-country migration flows to estimate the social weight of each factor. The underlying idea is simple: individuals implicitly evaluate the importance of local living conditions when deciding to migrate (Equation (2)).

$$
m p_{i t}=\alpha_{0}+\beta_{k} F_{i k t}+v_{i}+\varepsilon_{i t}
$$

where $m p_{i t}$ is net migration into region I normalized by the total population of the region $i, \alpha_{0}$ is a constant, and $F_{i k t}$ is the value of factor $k$ in region $i$, at time t. Thus, $\beta_{\mathrm{k}}$ accounts for the impact of factor $\mathrm{k}\left(\mathrm{F}_{\mathrm{k}}\right)$ upon net migration, and was used as a weight in the construction of RDI. Finally, $\mathrm{v}_{\mathrm{i}}$ is the region-specific residual and $\varepsilon_{i t}$ is the residual with the usual white noise properties. Given the panel structure of data and the strict underlying assumptions of panel models, various models were estimated using specification and diagnostic tests to facilitate selection of the best one (see, for example, a handbook by Baltagi [43]). The RDI index takes the following form:

$$
\mathrm{RDI}_{\mathrm{it}}=\mathrm{h}\left(\beta_{\mathrm{kt}}, \mathrm{F}_{\mathrm{ikt}}\right)=\sum_{\mathrm{k}} \beta_{\mathrm{k}} \times \mathrm{F}_{\mathrm{ikt}}
$$

where $\mathrm{RDI}_{\mathrm{it}}$ is the Rural Development Index in region $\mathrm{i}$ and year $\mathrm{t}, \mathrm{F}_{\mathrm{ikt}}$ is the factors as defined under Equation (2), and $\beta_{\mathrm{kt}}$ is the weights for each factor specific to region $\mathrm{i}$ and time $t$ resulting from the estimation of the migration function (2). That is, Equation (3) calculates the RDI as the proportion of migration flows explained by local characteristics represented by the factors.

Third, we evaluated the impact of RDP on LAU1 regions (see the textbook of Cerulli [44] for a detailed discussion on impact evaluation). While in standard policy analysis settings, sample-average treatment effects cannot be calculated because only one of the two possible outcomes for each region can be observed, this issue was solved by the estimated indicators that allowed the creation of the counterfactual. The counterfactual analytical framework developed by Rosenbaum and Rubin [45] and the employment of propensity score matching enabled us to predict the probability of a region being subsidized on the basis of observed covariates for both subsidized and non-subsidized regions. The method balances the observed covariates between the subsidized and non-subsidized regions based on the similarity between the predicted probabilities of a region being selected as a treated region. The most common evaluation parameter of interest is the Average Treatment Effect on the Treated (ATT), defined in Equation (4) as:

$$
\left.\mathrm{ATT}=\mathrm{E}\left(\mathrm{Y}_{1}-\mathrm{Y}_{0} \mid \mathrm{D}=1\right)=\mathrm{E}\left[\mathrm{Y}_{1} \mid \mathrm{D}=1\right)-\left(\mathrm{Y}_{0} \mid \mathrm{D}=1\right)\right]
$$

where $Y_{0}$ and $Y_{1}$ are the outcomes in the non-treated and treated states, respectively. Estimating the treatment effects based on Propensity Score Matching (PSM) requires making two assumptions. First, the Conditional Independence Assumption (CIA) states that for a given set of covariates participation is independent of potential outcomes. The second condition is that the ATT is only defined within the region of common support. For a more comprehensive discussion of the econometric theory behind this methodology, we refer the reader to the works of Imbens and Wooldridge [46] and Guo and Fraser [47].

For the empirical analysis, we employed two approaches: difference-in-differences treatment effect estimations combining PSM, and generalized propensity score matching. The advantage of the first approach is that it can evaluate treatment effects in a dynamic setting, making full use of 
our panel dataset. Having data about subsidized and non-subsidized regions over time can also help with accounting for some unobserved selection bias by combining PSM and the Difference-in Differences estimator (conditional DID estimator). The conditional DID estimator (e.g., [48]) is very applicable in the case that the outcome data about program participants (i.e., subsidized regions) and nonparticipants (non-subsidized regions) are available for both "before" and "after" periods (2008 and 2013, respectively). In our study, PSM-DID measured the impact of the subsidies by using the differences in selected outcome indicator (ATE or ATT) between subsidized $(D=1)$ and non-subsidized sub regions $(D=0)$ in the before and after situations. The main advantage of the PSM-DID estimator is that it can relax the assumption of unconfoundedness.

All LAU1 regions in our study received some support. Thus, in the binary PSM framework, the treated/non-treated division of the regions may only be done using arbitrary thresholds. Recent developments in applied econometrics, however, allowed us to implement Generalized Propensity Score Matching, as originally proposed by Gelman and Meng [49] for continuous treatment effects. As the second approach to evaluation described in this paper, GPS eliminates the subjectivity that can occur when classifying regions into treated and non-treated ones. While in a binary PSM setting logit or probit is used to estimate the probability of a unit (region) being treated conditioned on covariates $\mathrm{X}$, with continuous treatment parametric generalized linear models are used to estimate GPS using alternative distributional assumptions. More specifically, it is assumed that:

$$
\mathrm{g}\left(\mathrm{T}_{\mathrm{i}} \mid \mathrm{X}_{\mathrm{i}}\right) \sim \psi\left\{\mathrm{h}\left(\gamma, \mathrm{X}_{\mathrm{i}}\right), \sigma^{2}\right\}
$$

where $g$ is a link function (e.g., logarithm), $\psi$ is the probability density function (e.g., normal, gamma, igamma, or beta), $\mathrm{h}$ is a flexible, $\mathrm{X}$ covariate vector and unknown $\gamma$ parameter dependent function, and $\sigma^{2}$ is a scale parameter. $T_{i}$ is the treatment variable. Following the estimation by maximum likelihood of the treatment conditional distribution parameters $\gamma$ and $\sigma^{2}$, the GPS is estimated:

$$
\mathrm{GPSS}=\frac{1}{\sqrt{2 \pi \hat{\sigma}^{2}}} \exp \left[-\frac{1}{2 \hat{\sigma}^{2}}\left\{\mathrm{~g}\left(\mathrm{~T}_{\mathrm{i}}\right)-\mathrm{h}\left(\hat{\gamma}, \mathrm{X}_{\mathrm{i}}\right)\right\}\right]
$$

Similar to the PSM method, GPS also requires that covariates are sufficiently balanced across units with different treatment levels. [50] implemented the method developed by Flores et al. [51] using likelihood ratio tests. This consists of estimating three regressions (the dependent variable is the continuous treatment variable): one unrestricted which includes both the $\mathrm{X}$ covariates and GPS scores, and two restricted ones, one including X covariates only, and one including GPS terms only.

Dose-response and average treatment effect functions are then derived. For the research described in this paper, we employed the semi-parametric approach using Inverse Weighting Kernel, Second-Order Penalized Spline, and Radial Spline methods developed by Bia et al. [50]. For robustness, we complemented our estimations with the (parametric) generalized linear model approach suggested by Guardabascio and Ventura [52]. Within the parametric dose-response estimations, the balancing property is checked by dividing the treatment sample into subsamples and testing whether pre-treatment variables given a GPS score are significantly different in individual treatment intervals. The conditional expectation of outcomes is estimated using parametric methods, similar to Equation (7):

$$
Y_{i}=\beta_{0}+\beta_{1} T_{i}+\beta_{2} T_{i}^{2}+\beta_{3} G_{P S}+\beta_{4} G S_{I}^{2}+\beta_{5} T_{i} G_{P S}
$$

\section{Results}

\subsection{Estimation of the Rural Development Index}

Equation (2) was first estimated as a fix and random effects panel model; the Hausman test, however, rejected the random-effects model $\left(\mathrm{chi}^{2}(29)=114.6 ; p=0.000\right)$. Further, the 
homoscedasticity assumption in the fixed-effects model was rejected by the modified Wald test for group heteroscedasticity (see [53], p. 58) at $\operatorname{chi}^{2}(174)=3730.3 ;(p=0.000)$. In addition, the Wooldridge $([54,55])$ test for first-order autocorrelation in panel data also rejected the null assumption $(\mathrm{F}(1173)=34.96 ; p=0.000)$. Considering the results of these statistical tests, linear regression methods with panel-corrected standard errors that allow for heteroscedastic and contemporaneously correlated disturbances across panels were employed (we used the xtpsce routine available in Stata). The estimation results of Equation (2) using panel-corrected standard errors model are presented in the first two columns of Table 3.

Table 3. Migration function models (dependent variable net migration into a region, normalized by population).

\begin{tabular}{|c|c|c|c|c|c|}
\hline \multicolumn{2}{|c|}{ Non-Spatial Model } & \multicolumn{4}{|c|}{ Spatial Durbin Model } \\
\hline Var. & Coeff. & Var. & Coeff. & Var. & Coeff. \\
\hline f1 & $0.00376^{* * *}$ & $\mathrm{f} 1$ & $0.00363^{* * *}$ & w_f1 & -0.00038 \\
\hline $\mathrm{f} 2$ & $0.00273^{* * *}$ & $\mathrm{f} 2$ & $0.00390^{* * *}$ & $\mathrm{w} f 2$ & 0.00003 \\
\hline f3 & $0.00101^{* * *}$ & $\mathrm{f} 3$ & $0.00061^{* * *}$ & $\mathrm{w} \_\mathrm{f} 3$ & 0.00241 \\
\hline $\mathrm{f} 4$ & 0.00010 & $\mathrm{f} 4$ & 0.00020 & $\mathrm{w} \_\mathrm{f} 4$ & -0.00103 \\
\hline f5 & $0.00063^{* * *}$ & f5 & $0.00048^{* * *}$ & w_f5 & -0.00030 \\
\hline f6 & $-0.00036^{* *}$ & f6 & $-0.00072^{* * *}$ & $\mathrm{w} \_\mathrm{f} 6$ & 0.00046 \\
\hline $\mathrm{f} 7$ & -0.00013 & f7 & 0.00022 & $\mathrm{w}$ f7 & 0.00088 \\
\hline f8 & $0.00055^{* * *}$ & f8 & $0.00040^{* * *}$ & $\mathrm{w} \_\mathrm{f} 8$ & 0.00220 * \\
\hline f9 & 0.00004 & f9 & 0.00004 & $\mathrm{w} \_\mathrm{f} 9$ & -0.00173 \\
\hline $\mathrm{f} 10$ & $-0.00054^{* * *}$ & $\mathrm{f} 10$ & $-0.00035^{* * *}$ & $\mathrm{w} \_\mathrm{f} 10$ & -0.00109 \\
\hline $\mathrm{f} 11$ & 0.00000 & $\mathrm{f} 11$ & 0.00002 & w_f11 & 0.00006 \\
\hline $\mathrm{f} 12$ & -0.00000 & $\mathrm{f} 12$ & 0.00006 & $\mathrm{w} \_\mathrm{f} 12$ & $-0.0020^{* *}$ \\
\hline $\mathrm{f} 13$ & $0.00093 * * *$ & $\mathrm{f} 13$ & $0.00070^{* * *}$ & w_f13 & 0.00126 \\
\hline f14 & $-0.00031^{* *}$ & $\mathrm{f} 14$ & -0.00021 & w_f14 & $0.00221 *$ \\
\hline $\mathrm{f} 15$ & $0.00016^{* *}$ & $\mathrm{f} 15$ & $0.00032^{* * *}$ & w_f15 & -0.00107 \\
\hline f16 & $-0.00094^{* * *}$ & f16 & -0.00031 * & w_f16 & 0.00005 \\
\hline $\mathrm{f} 17$ & 0.00004 & $\mathrm{f} 17$ & -0.00006 & $\mathrm{w} \_\mathrm{f} 17$ & $0.0036^{* *}$ \\
\hline $\mathrm{f} 18$ & 0.00021 & $\mathrm{f} 18$ & $-0.00052^{* * *}$ & w_f18 & -0.00114 \\
\hline f19 & $0.00143^{* * *}$ & f19 & $0.00054^{* * *}$ & w_f19 & $0.0032^{* * *}$ \\
\hline f 20 & -0.00006 & $\mathrm{f} 20$ & -0.00003 & w_f 20 & $0.00414^{* * *}$ \\
\hline $\mathrm{f} 21$ & -0.00002 & $\mathrm{f} 21$ & -0.00005 & $\mathrm{w} \_\mathrm{f} 21$ & 0.00151 \\
\hline $\mathrm{f} 22$ & $0.00019^{* *}$ & $\mathrm{f} 22$ & $0.00030^{* * *}$ & w_f22 & 0.00115 \\
\hline $\mathrm{f} 23$ & $0.00053^{* * *}$ & $\mathrm{f} 23$ & $0.00030^{* * *}$ & w_f 23 & -0.00073 \\
\hline f 24 & 0.00008 & $\mathrm{f} 24$ & $0.00032^{* *}$ & w_f 24 & $0.00319^{* * *}$ \\
\hline f 25 & 0.00003 & $\mathrm{f} 25$ & -0.00013 & w_f 25 & $-0.0029^{* * *}$ \\
\hline f 26 & 0.00039 ** & f26 & 0.00031 * & w_f26 & -0.00201 \\
\hline $\mathrm{f} 27$ & -0.00015 & $\mathrm{f} 27$ & $0.00056^{* * *}$ & $\mathrm{w} \_\mathrm{f} 27$ & $-0.0026^{* * *}$ \\
\hline f 28 & -0.00020 & $\mathrm{f} 28$ & 0.00004 & w_f28 & 0.00083 \\
\hline f 29 & $-0.00036^{*}$ & $\mathrm{f} 29$ & -0.00009 & w_f29 & $-0.00115^{* *}$ \\
\hline cons & $-0.00275^{* * *}$ & cons & $-0.00282^{* * *}$ & & \\
\hline $\mathrm{N}$ & 1044 & 1044 & & & \\
\hline Cross-sections & 174 & 174 & & & \\
\hline$R^{2} a$ & 0.5662 & 0.6162 & & & \\
\hline 11 & 4308.04 & 4390.3 & & & \\
\hline Wald (p) & 0.0000 & 0.0000 & & & \\
\hline
\end{tabular}

Source: Own estimations. ${ }^{*}, * *$, and ${ }^{* * *}$ denote $10 \%, 5 \%$ and $1 \%$ significance levels, respectively. $\mathrm{N}$ denotes the total number of observations, Cross-sections the number of cross sections, $\mathrm{R}^{2} \mathrm{a}$ the percentage of total variance explained by the model, 11 the loglikelihood, and (p) the Wald regression significance.

Due to the use of spatially distributed data, we also faced the issue of spatial correlation (for an up-to-date discussion of spatial models, see [56]. Table 4 presents a wealth of spatial autocorrelation test results. Clearly, the non-spatial model (first two columns) suffered from rather severe spatial autocorrelation, all null hypotheses being rejected. We proceeded with the sequential estimation of various spatial models (Spatial Autoregressive Model, Spatial Error Model, and Spatial Durbin Model), using the linear-panel-corrected standard error estimator (the user written spregxt command in Stata was used for this purpose). 
Table 4. Spatial autocorrelation test results ( $p$-values reported).

\begin{tabular}{ccc}
\hline & Non-Spatial Model & Spatial Durbin Model \\
\hline & $\mathbf{H}_{\mathbf{0}}$ : Error has no Spatial Autocorrelation \\
\hline Global Moran MI & 0.0000 & 0.2697 \\
Global Geary GC & 0.0000 & 0.0616 \\
Global Getis-Ords GO & 0.0000 & 0.2697 \\
Moran MI Error Test & 0.0000 & 0.2562 \\
LM Error (Burridge) & 0.0000 & 0.2505 \\
LM Error (Robust) & 0.0000 & 0.3083 \\
H: Spatial lagged Dependent Variable has no Spatial Autocorrelation \\
\hline LM Lag (Anselin) & 0.0000 & 0.2453 \\
LM Lag (Robust) & 0.0000 & 0.3017 \\
& $\mathbf{H}_{\mathbf{0}}:$ & \\
\hline LM SAC (LMErr+LMLag_R) & 0.0000 & 0.3031 \\
\hline
\end{tabular}

The null hypothesis of no spatial autocorrelation of any form was not rejected by the Spatial Durbin Model only; the $p$-values of test statistics are presented in the last two columns of Table 4 . Thus, the latter model was preferred. Column 4 in Table 3 lists the coefficients of factor variables, and Column 6 their spatial counterparts.

In total, 27 variables were significant, mostly at the $1 \%$ level, 17 from the factor variables and 10 from their spatial counterpart. The model explained $61 \%$ of the variation of internal net migration. Thus, RDIs (Equation (4)) were estimated as fitted values of the Spatial Durbin Model, i.e. the proportion of net migration rate explained by local, objective factors.

Inspection of the ten highest and lowest RDI indices confirmed what seems intuitive: RDI is lowest in the northeast, east, and southwest of Hungary (e.g., the Ózd, Berettyóújfalú, and Fehérgyarmat regions) while the high RDI regions are clustered around the capital, Budapest (e.g., Gödöllo, Ráckeve, Dunakeszi, and Budapest regions) and in the northwest. The RDIs display high correlation indices across the timespan, suggesting the stability of development rankings over the years. Regional RDI levels for the beginning and end of the period under examination are presented in Figure 2a. Regions are sorted into quantiles, coded from highest ranking (darkest shade) to lowest (lightest shade).

Results also confirm our intuition: LAU1 regions in the east/northeast and southwest (bordering Romania, Ukraine, Slovakia and Serbia/Croatia, respectively) are less developed, while the center of Hungary, and the west and northwest (bordering Austria, Slovakia, and, to some extent, Slovenia) are the most developed. Inspection of the graphs does not reveal the major changes that took place between the start and end of the programming period, albeit some regions changed their status.

Figure 2B complements the picture of the development of Hungarian regions. It depicts internal migration flow relative to the size of local, LAU1, and population (NMR). The argument for also using relative migration is that the government, faced with the depopulation of areas, may choose to target with subsidies these areas, irrespective of the planned or objective level of development.

As expected, the maps in Figure 2a,b are quite similar, yet the correlation indices between indicators emphasize non-trivial differences (see the correlation in Table A1 in Appendix A). Thus, impact analysis should provide more robust results with both development indicators. To analyze the changes in the RDI throughout the period, Figure 3a shows the change in RDI between 2008 and 2013. As expected from a policy point of view, the largest changes (darkest shade) are indeed concentrated in the less developed regions, and the least in already developed Central and Western Hungary (lightest shade). Thus, it appears from an objective perspective that some convergence between Hungarian regions is happening. 

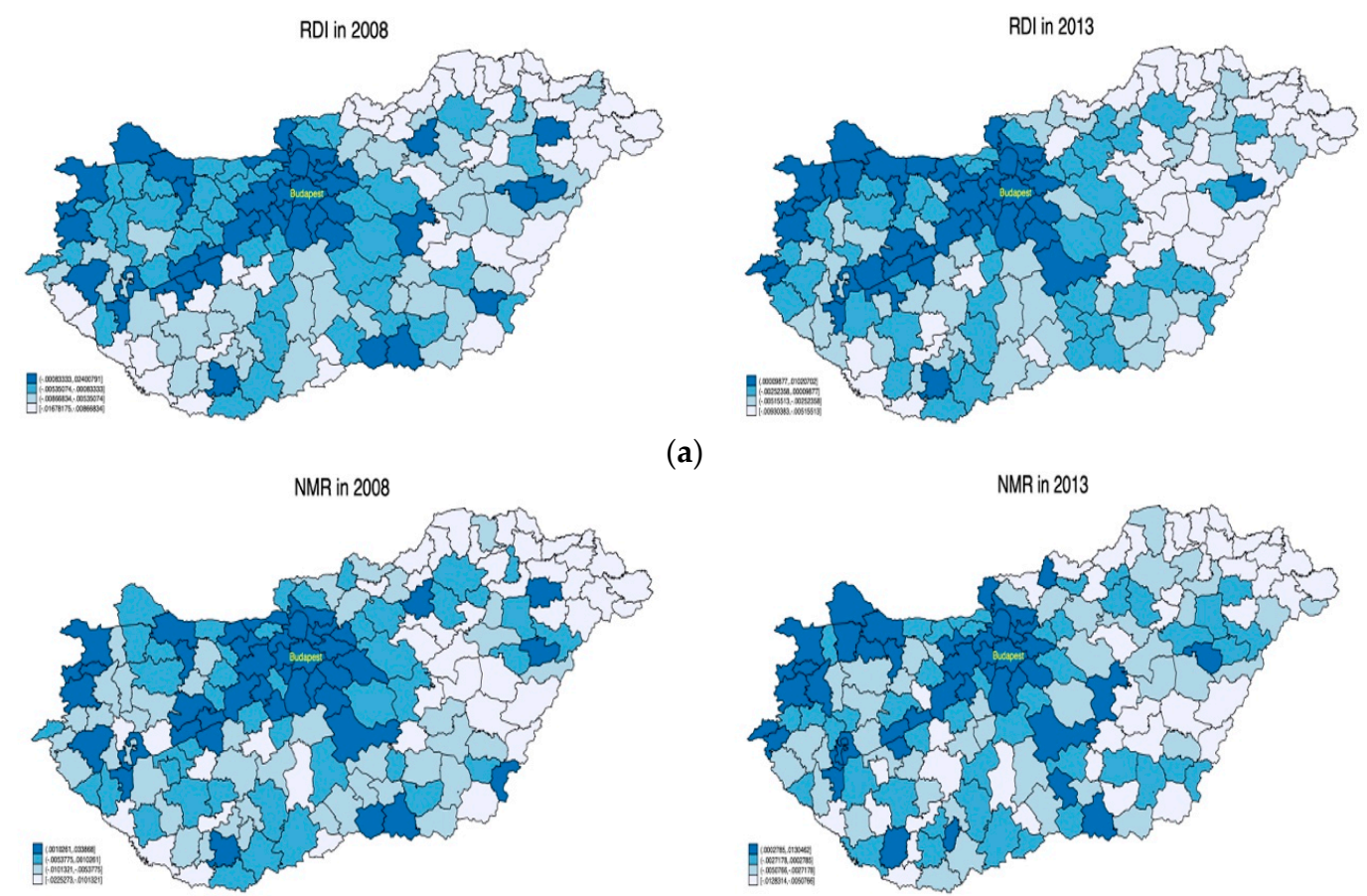

(a)

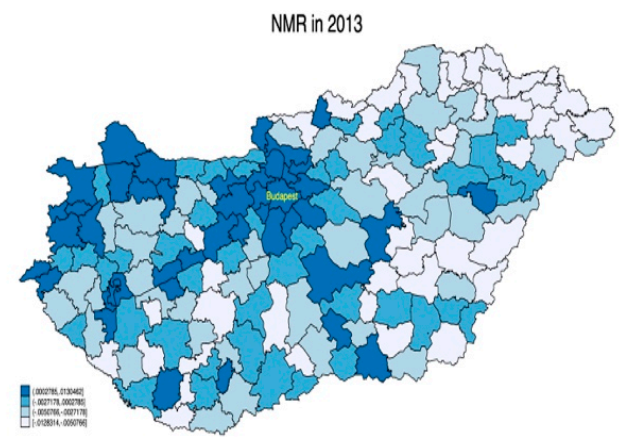

(b)

Figure 2. Levels of rural development in 2008 and 2013 (RDI). Source: Own calculations, using spmap (Stata) (a). Levels of rural development in 2008 and 2013 (NMR). Source: Own calculations, using spmap (Stata) (b).

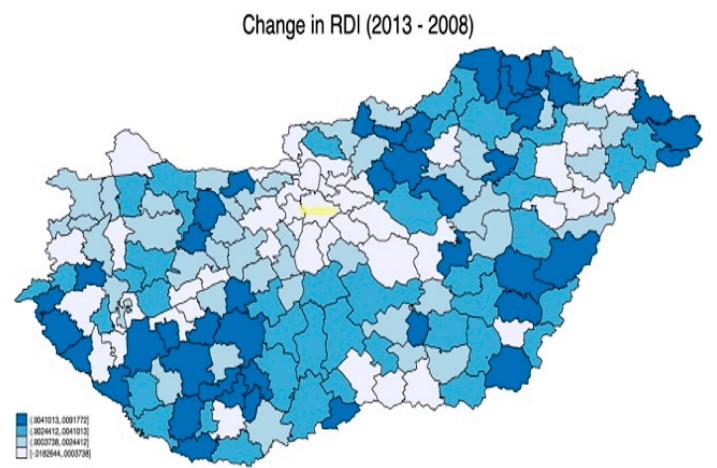

(a)

Change in NMR (2013 - 2008)

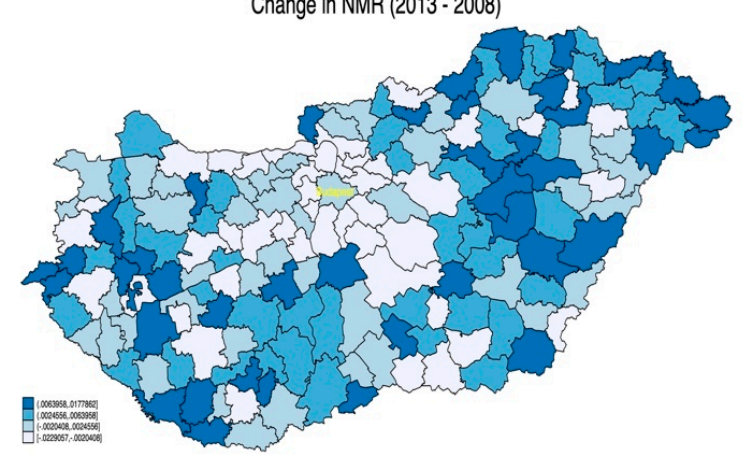

(b)

Figure 3. (a) Change in regional development between 2008 and 2013 (RDI). Source: Own calculations, using spmap (Stata); (b) Change in regional development between 2008 and 2013 (NMR). Source: Own calculations, using spmap (Stata). 
Graphical evidence suggests that less-favored regions have increased their relative levels of development more (on average) than already developed regions; this is presumably in line with policy aims. The situation, however, is less positive if we look at the change between relative migration (Figure 3b) between 2013 and 2008. The map emphasizes that development policy did not put a halt to outmigration from the poorest Hungarian regions; indeed, the rate accelerated between 2008 and 2013.

Now, turning our attention to the impact of development funds, in our analysis, we specifically focused on rural development subsidies, $75 \%$ of which are paid by the EU, and $25 \%$ by Hungary in the form of co-financing. In the Introduction, we emphasize the magnitude and importance of these payments. With respect to subsidies, Figures 4-6 depict the regional intensity of total, per capita, and per square $\mathrm{km}$ subsidies received. Their geographical distribution is less obvious compared to that illustrated on the rural development maps. It can however be seen that less developed regions benefited most from support, especially in terms of per capita or per $\mathrm{km}^{2}$ subsidies.
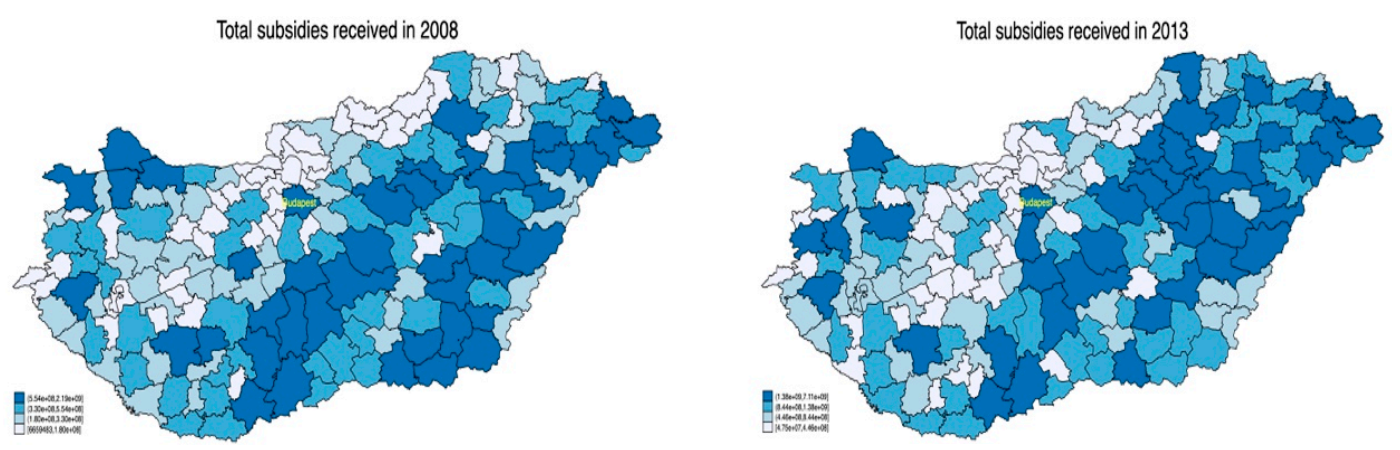

Figure 4. Total subsidies received in 2008 and 2013 Source: Own calculations, using spmap (Stata).
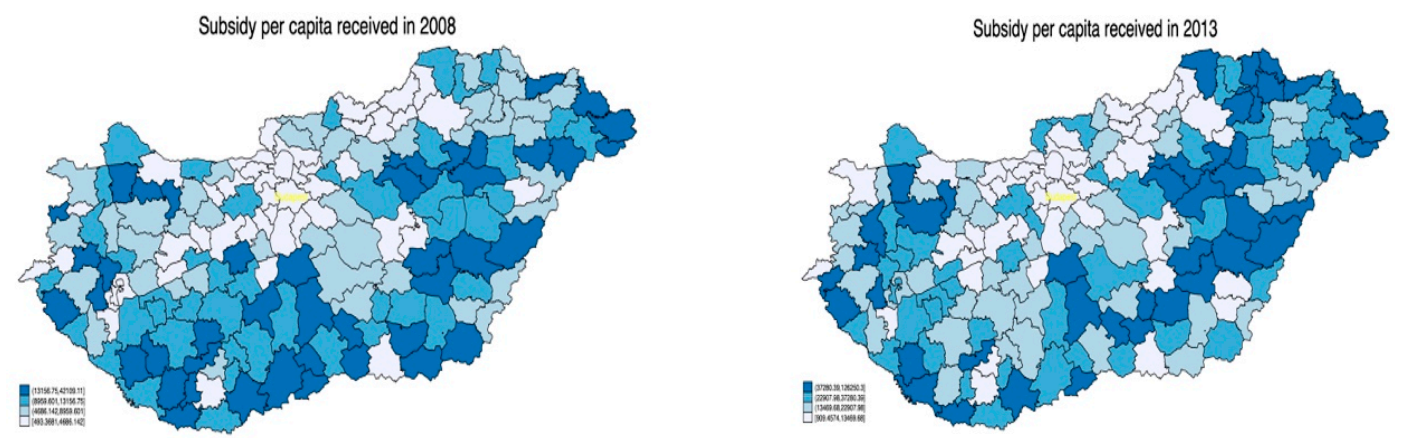

Figure 5. Per capita subsidies received in 2008 and 2013. Own calculations, using spmap (Stata).
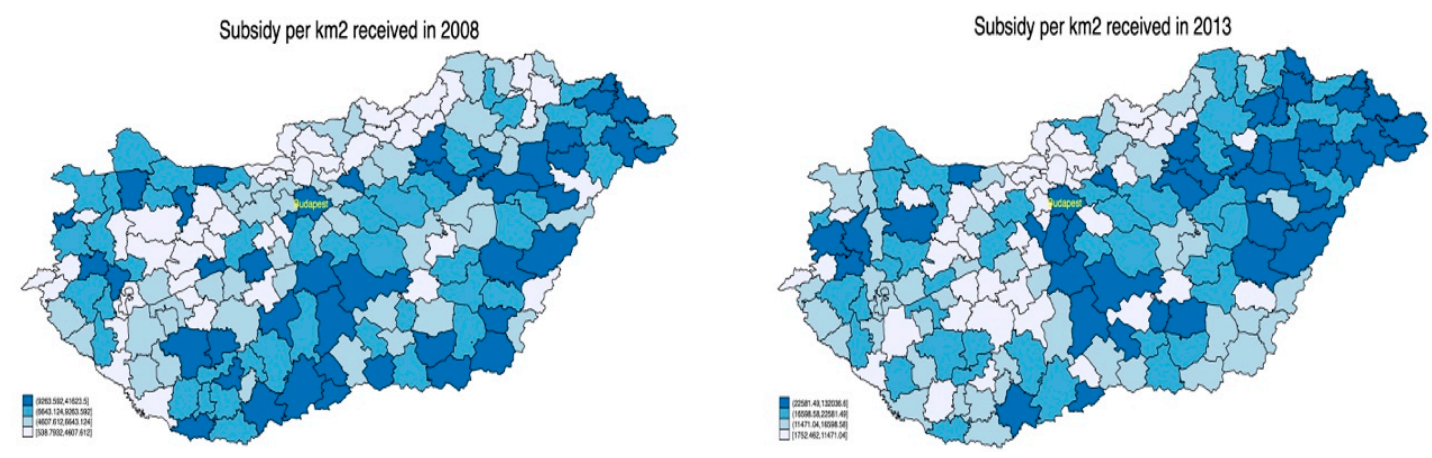

Figure 6. Subsidies per square km received in 2008 and 2013. Own calculations, using spmap (Stata).

\subsection{Difference in Differences Estimation Results}

In line with the current literature, we analyzed the impact of regional development subsidies using PSM-DID estimations and generalized propensity score matching (we used the diff, gpscore, 
glmdose, and doseresponse Stata routines). The estimated propensity score is actually the probability of participation in a program (treatment), conditioned on control variables calculated for all regions.

We start with the results of PSM-DID, which can help overcome hidden bias, and generally may improve non-experimental program evaluation. We used a kernel matching algorithm for the PSM-DID estimations $([57,58])$ while the balancing property was assessed using t-tests for covariate mean equality between treated and control regions.

There are two key issues here. The first is how the baseline and end periods were defined. Since we had data for six years, for robustness, three definitions were used: first, the two extreme years (2008 and 2013), followed by the first two and last two years, and finally, the first three and last three years of our panel. The second issue-since all regions received some support in all periods-is how the treated and non-treated regions are defined. We employed two approaches here. First, similar to $[15,23]$, we used an arbitrary threshold to define the binary subsidy variables: areas where support intensity was more than two-thirds of the yearly median subsidy were qualified as treated. We then complemented the previous approach and overcame the subjectivity of threshold choice by splitting the sample into five quantiles. The lower two quantiles were considered as not-supported and the upper two as supported, while the middle quantile was omitted from the analysis. Thus, we were able to directly compare the performance of low support with high support intensity regions. Tables 5 and 6 display the results of the PSM-DIDs estimated for the three subsidy variables, two outcomes, and three definitions of baseline-end periods using the threshold and quantile treatment definition approaches, respectively.

Table 5. Diff-in-diff treatment effect (PSM-DID) results for total subsidy, subsidy per cap. and subsidy per $\mathrm{km}^{2}$ - threshold approach.

\begin{tabular}{|c|c|c|c|c|c|c|c|c|c|}
\hline & \multicolumn{3}{|c|}{ Total Subsidy } & \multicolumn{3}{|c|}{ Subsidy/Cap } & \multicolumn{3}{|c|}{ Subsidy/km² } \\
\hline & Coeff. & Prob. & No ${ }^{\#}$. & Coeff. & Prob. & No ${ }^{\#}$. & Coeff. & Prob. & No ${ }^{\#}$. \\
\hline \multicolumn{10}{|c|}{ Baseline period: 2008, end period: 2013} \\
\hline RDI & -0.004 & 0.084 & 8 & 0.000 & 0.981 & 17 & -0.004 & 0.046 & 12 \\
\hline NMR & -0.001 & 0.733 & 8 & 0.003 & 0.253 & 17 & -0.002 & 0.739 & 11 \\
\hline \multicolumn{10}{|c|}{ baseline period: $2008-2009$, end period: $2012-2013$} \\
\hline RDI & -0.004 & 0.012 & 17 & -0.004 & 0.048 & 16 & -0.003 & 0.037 & 7 \\
\hline NMR & -0.003 & 0.122 & 18 & -0.002 & 0.272 & 14 & -0.000 & 0.904 & 5 \\
\hline \multicolumn{10}{|c|}{ baseline period: 2008-2010, end period: $2011-2013$} \\
\hline RDI & -0.003 & 0.045 & 18 & -0.003 & 0.006 & 12 & -0.002 & 0.137 & 7 \\
\hline NMR & -0.002 & 0.456 & 17 & 0.000 & 0.890 & 12 & -0.002 & 0.209 & 3 \\
\hline
\end{tabular}

For each subsidy and outcome category, we present the coefficient of the ATT (see Equation (4)), its significance (calculated with 200 bootstrap replications) and the number of unmatched covariates (significant t-test results at a $5 \%$ level of significance). The matching results are quite mixed. The number of unmatched covariates varied between three, or $10 \%$ (quantile approach, subsidy/cap, baseline 2008, end period 2013 and threshold approach, subsidy $/ \mathrm{km}^{2}$, baseline 2008-2010, end 2011-2013) and 68\% (quantile approach, total subsidy, baseline 2008-2010, end period 2011-2013). However, even if we only considered best matching results (for example, where more than half of covariates were matched between treated and non-treated groups), all results point in the same direction: there were mostly insignificant treatment effects, regardless of outcome or support definition. Even more surprisingly is that where effects were significant ( $30 \%$ of all cases), they were small and negative. 
Table 6. Diff-in-diff treatment effect (PSM-DID) results for total subsidy, subsidy per cap. And subsidy per $\mathrm{km}^{2}$ - quantile approach.

\begin{tabular}{|c|c|c|c|c|c|c|c|c|c|}
\hline & \multicolumn{3}{|c|}{ Total Subsidy } & \multicolumn{3}{|c|}{ Subsidy/cap } & \multicolumn{3}{|c|}{ Subsidy $/ \mathrm{km}^{2}$} \\
\hline & Coeff. & Prob. & No ${ }^{\#}$. & Coeff. & Prob. & No ${ }^{\#}$. & Coeff. & Prob. & No ${ }^{\#}$. \\
\hline \multicolumn{10}{|c|}{ baseline period: 2008, end period: 2013} \\
\hline RDI & 0.001 & 0.634 & 9 & 0.001 & 0.592 & 4 & 0.003 & 0.290 & 12 \\
\hline NMR & -0.001 & 0.869 & 9 & 0.002 & 0.456 & 3 & 0.004 & 0.287 & 12 \\
\hline \multicolumn{10}{|c|}{ baseline period: 2008-2009, end period: 2012-2013 } \\
\hline RDI & -0.003 & 0.089 & 17 & -0.004 & 0.037 & 18 & -0.002 & 0.185 & 6 \\
\hline NMR & -0.002 & 0.358 & 17 & -0.006 & 0.027 & 18 & -0.003 & 0.100 & 5 \\
\hline \multicolumn{10}{|c|}{ baseline period: 2008-2010, end period: 2011-2013 } \\
\hline RDI & -0.003 & 0.550 & 19 & -0.001 & 0.360 & 14 & -0.003 & 0.137 & 11 \\
\hline NMR & -0.001 & 0.686 & 20 & -0.005 & 0.088 & 16 & 0.001 & 0.721 & 12 \\
\hline
\end{tabular}

Source: Own estimations. " indicates the number of unmatched covariates (total number of covariates is 29). $p$-values were calculated using bootstrapped standard errors. Coefficients in bold denote a $10 \%$ significance level. Common support was imposed.

\subsection{Generalized Propensity Score Matching Results}

Next, we discuss the results obtained using generalized propensity score matching methods. Earlier researchers were forced to apply Box-Cox transformation to render the treatment variables normal. Newer GPS routines now allow a wider class of distributions. In our case, the distribution of treatment variables clearly does not follow a normal distribution (for simple graphical evidence of this, see Figure A2 in Appendix A), thus we used a gamma distribution with a logarithmic link function in the GPS estimations. The per capita and per $\mathrm{km}^{2}$ subsidy variables were divided by 1000 , and the total subsidy by 1,000,000 for the empirical analysis. GPS estimations required us to define treatment intervals. For semiparametric estimations, the dose-response and average treatment effect functions were evaluated at each level of the vectors: Total subsidy (million HUF): 200, 300, 400, 500, 600, 800, 1000, 1400, 2000, and 3000; Subsidy per capita (thousand HUF): 3, 5, 8, 10, 13, 16, 20, 25, 35, and 50; Subsidy per $\mathrm{km}^{2}$ (thousand HUF): 4, 6, 8, 10, 12, 15, 20, 25, 35, and 50. While these levels are arbitrary, but based on the distribution of treatment variables (see also Figure A3 in Appendix A), it should be noted that using 10 evenly spaced values to cover the range of the treatment or using 10 percentiles to cover the empirical distribution of the treatment variables leads to qualitatively the same results. Table 7 presents the balancing tests of semiparametric models.

Table 7. Assessment of balancing property of GPS-Likelihood Ratio tests, semiparametric approach.

\begin{tabular}{cccc}
\hline & Total Subsidy & Subsidy/Cap & Subsidy/km $^{\mathbf{2}}$ \\
\hline Restricted LL & -6825.18 & -3435.99 & -3475.80 \\
(covariates X) & -6815.67 & -3424.69 & -3463.51 \\
Unrestricted LL & 19.02 & 22.59 & 24.57 \\
Test statistic & 0.920 & 0.794 & 0.700 \\
p-value & 29 & 29 & 29 \\
N. of restrictions & -6929.93 & -3498.55 & -3534.69 \\
Restricted LL & -6815.18 & -3424.69 & -3463.51 \\
(GPS terms) & 228.53 & 147.72 & 142.34 \\
Unrestricted LL & 0.000 & 0.000 & 0.000 \\
Test statistic & 3 & 3 & 3 \\
p-value & 133 & 167 & 56 \\
N. of restrictions & N. obs. dropped ${ }^{\#}$ &
\end{tabular}


The unrestricted model is the GLM regression of each treatment variable on the $\mathrm{X}$ covariates and GPS score, including their square and cubic terms (unrestricted and restricted model estimations are available upon request). The null hypothesis that covariates may be excluded was not rejected, while the null hypothesis that GPS terms may be excluded was rejected at $p=0.000$ for all treatment variables. These results emphasize that subgroups were correctly matched. In addition, Table 7 emphasizes that, by imposing the common support condition, 133, 167 and 56 observations were omitted for Total subsidy, Subsidy per capita and Subsidy per $\mathrm{km}^{2}$ models, respectively. Turning our attention to the parametric estimations, four treatment intervals were defined for each subsidy variable: Total subsidy (million HUF): $[0,250),[250,500),[500,1000)$ and $[1000,7112)$; Subsidy per capita (thousand HUF): [0, $10),[10,20),[20,40)$ and $[40,127)$; and Subsidy per km ${ }^{2}$ (thousand HUF): $[0,8),[8,12),[12,20)$ and $[20,132)$. As described in the Methodology Section, balancing tests were conducted for each treatment interval. Table 8 includes a summary of these tests (complete results are available upon request).

Table 8. Assessment of balancing property of GPS-t-tests \#, parametric approach.

\begin{tabular}{cccc}
\hline & Total Subsidy & Subsidy/Cap & Subsidy $/ \mathbf{k m}^{\mathbf{2}}$ \\
\cline { 2 - 4 } & number of significant test statistics (out of 29) \\
\hline Treatment interval 1 & 5 & 7 & 3 \\
Treatment interval 2 & 1 & 2 & 2 \\
Treatment interval 3 & 5 & 4 & 3 \\
Treatment interval 4 & 5 & 4 & 1 \\
\hline
\end{tabular}

Source: Authors' calculations. " “Test that the conditional mean of the pre-treatment variables given the generalized propensity score is not different between units who belong to a particular treatment interval and units who belong to all other treatment intervals" [52].

The worst balancing results are for the subsidy per capita variable in the first treatment interval, where 7 of the 29 covariates were not balanced. The rest of the number of rejections varied between one and five; overall, the subsidy per $\mathrm{km}^{2}$ variable was the most balanced after accounting for GPS scores. With the wealth of covariates that was available (a total of 29), we may cautiously consider the balancing requirement satisfied. Note that this partial result is in line with the results of likelihood ratio tests for the semi-parametric approach. The most important results are depicted in the figures below. Figures 7-12 depict dose-response functions and average treatment effects (derivatives) using the Inverted Weighted Kernel, second order Penalized Spline, and Radial Penalized Spline methods, respectively, for the three treatment variables and two outcome variables.
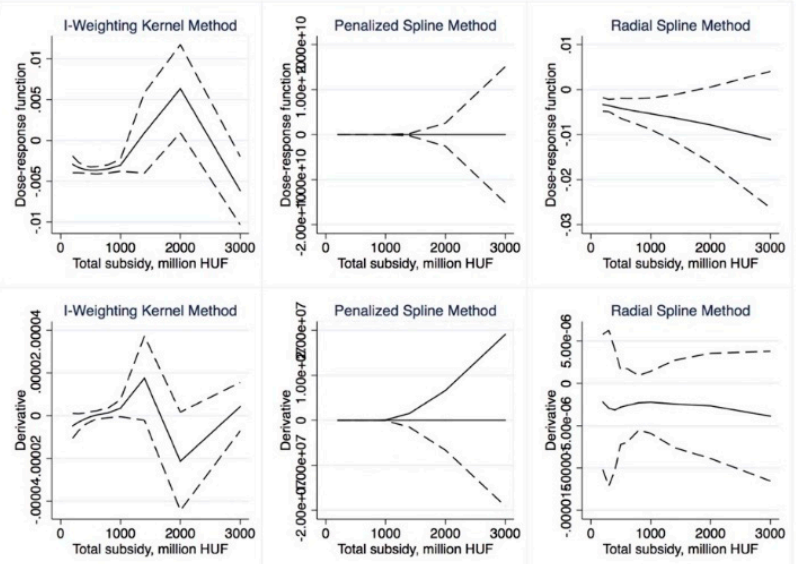

Figure 7. Semiparametric dose-response functions and average treatment effects with $95 \%$ confidence intervals (outcome is RDI, treatment is Total subsidy). Source: Own calculations using drf (Stata). 

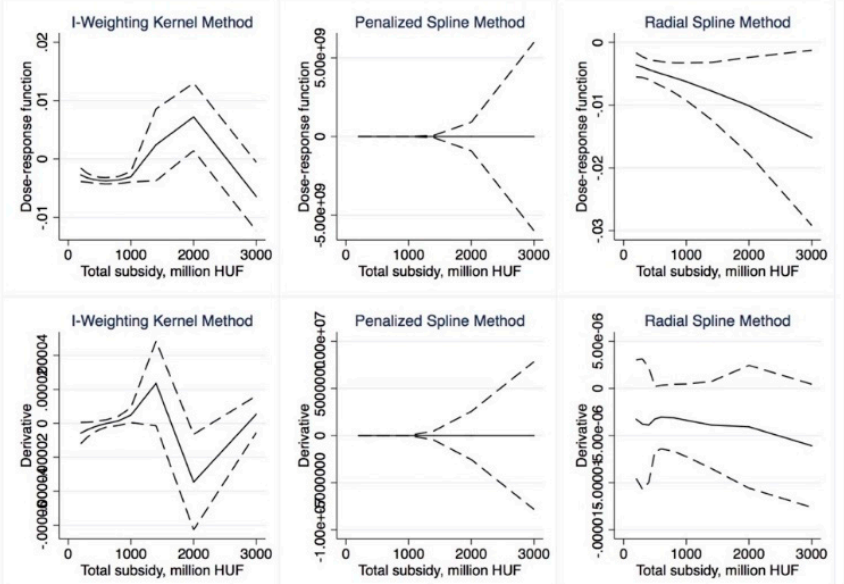

Figure 8. Semiparametric dose-response functions and average treatment effects with $95 \%$ confidence intervals (outcome is NMR, treatment is Total subsidy). Source: Own calculations using drf (Stata).
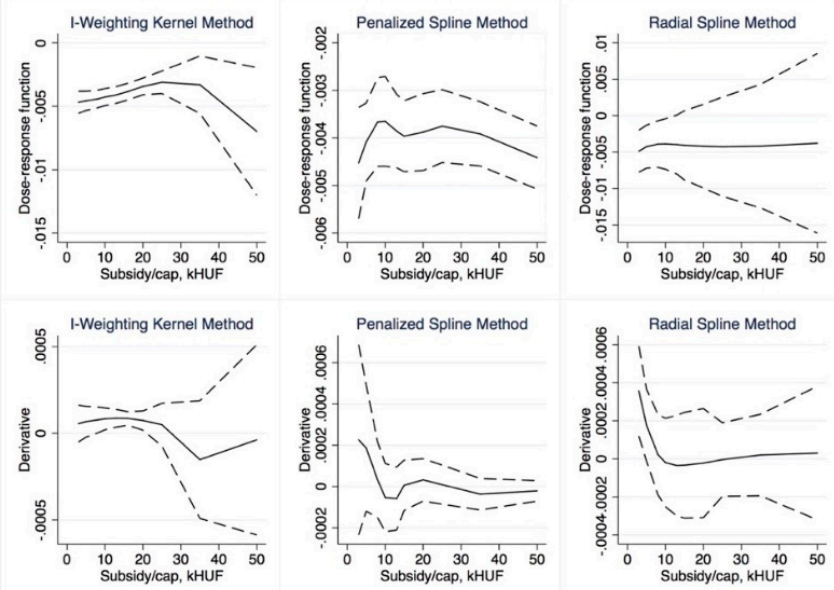

Figure 9. Semiparametric dose-response functions and average treatment effects with $95 \%$ confidence intervals (outcome is RDI, treatment is Subsidy per capita). Source: Own calculations using drf (Stata).
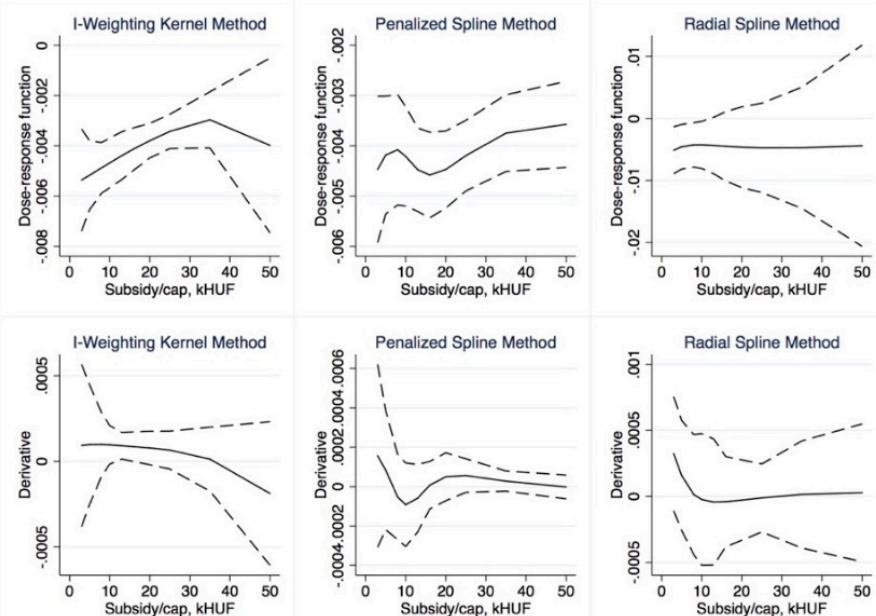

Figure 10. Semiparametric dose-response functions and average treatment effects with $95 \%$ confidence intervals (outcome is NMR, treatment is Subsidy per capita). Source: Own calculations using drf (Stata). 

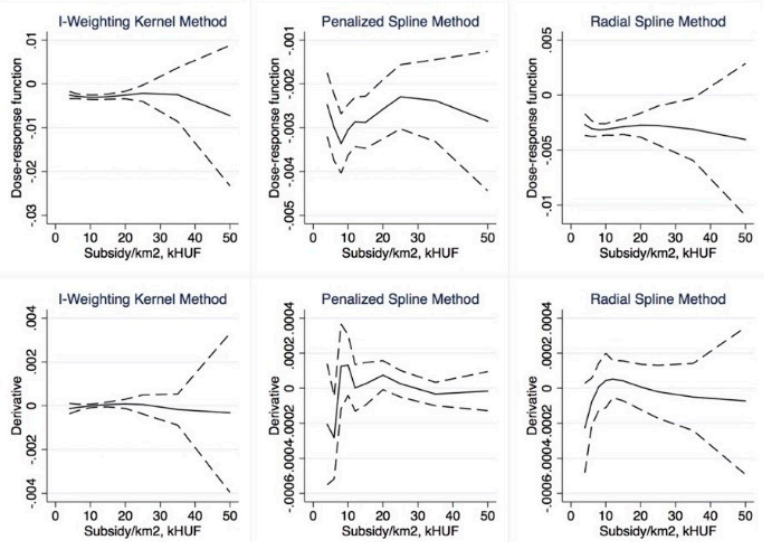

Figure 11. Semiparametric dose-response functions and average treatment effects with $95 \%$ confidence intervals (outcome is RDI, treatment is Subsidy per $\mathrm{km}^{2}$ ). Source: Own calculations using drf (Stata).
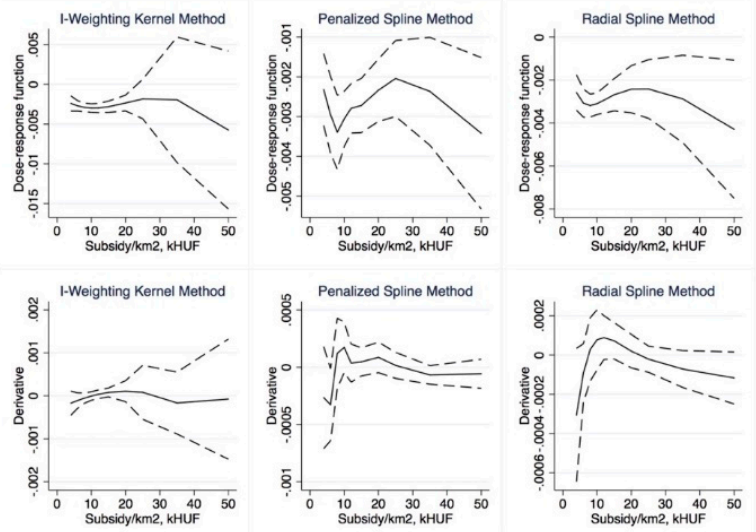

Figure 12. Semiparametric dose-response functions and average treatment effects with $95 \%$ confidence intervals (outcome is NMR, treatment is Subsidy per $\mathrm{km}^{2}$ ). Source: Own calculations using drf (Stata).

Figures 13-18 are the parametric counterparts of dose-response functions depicted above.
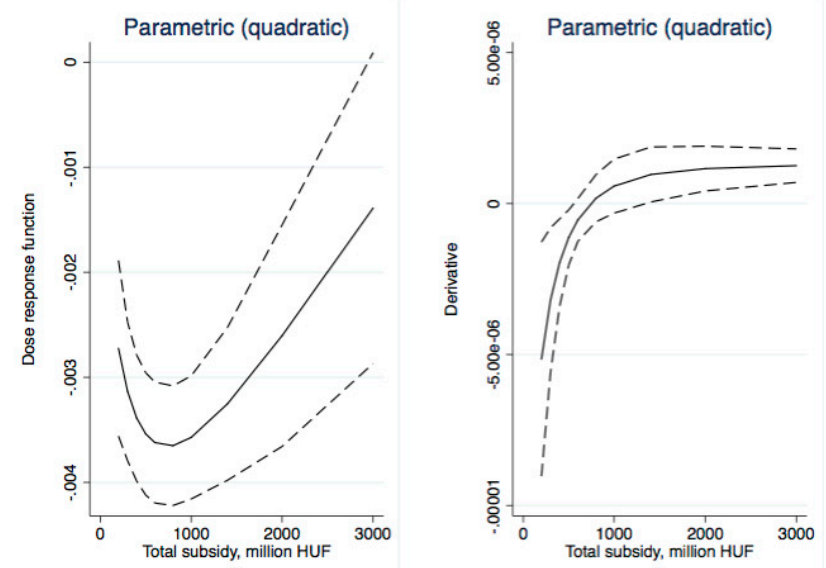

Figure 13. Parametric dose-response functions and average treatment effects with $95 \%$ confidence intervals (outcome is RDI, treatment is Total subsidy). Source: Own calculations using glmdose (Stata). 

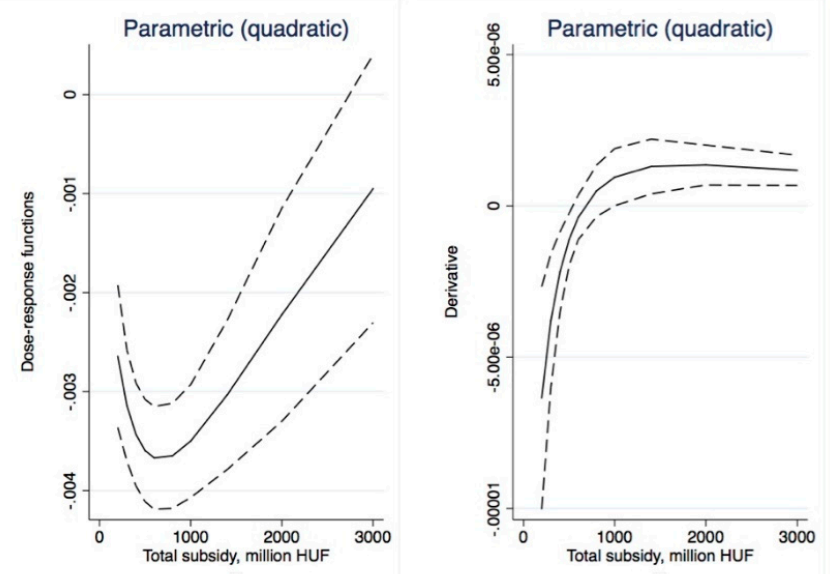

Figure 14. Parametric dose-response functions and average treatment effects with $95 \%$ confidence intervals (outcome is NMR, treatment is Total subsidy). Source: Own calculations using glmdose (Stata).
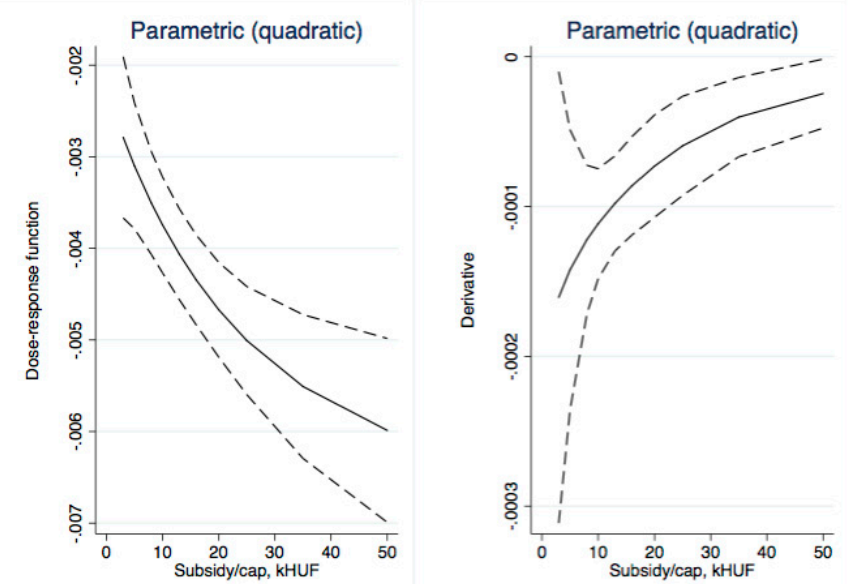

Figure 15. Parametric dose-response functions and average treatment effects with $95 \%$ confidence intervals (outcome is RDI, treatment is Subsidy per capita). Source: Own calculations using glmdose (Stata).
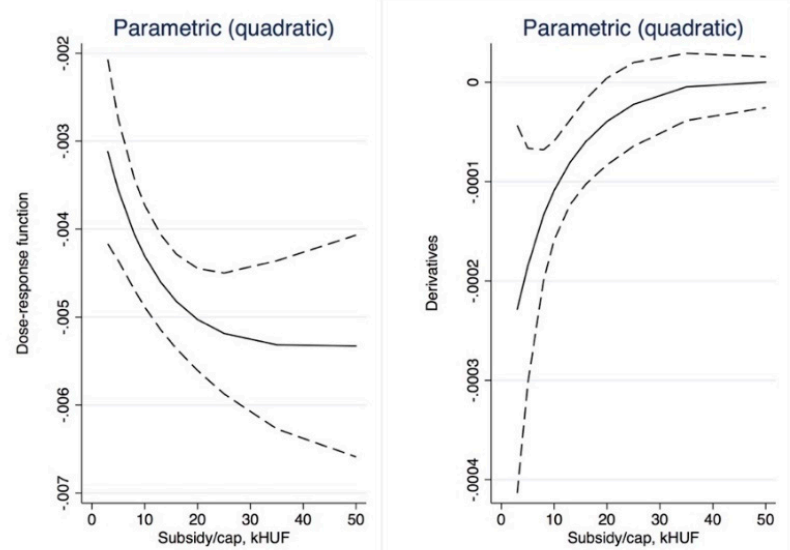

Figure 16. Parametric dose-response functions and average treatment effects with $95 \%$ confidence intervals (outcome is NMR, treatment is Subsidy per capita). Source: Own calculations using glmdose (Stata). 

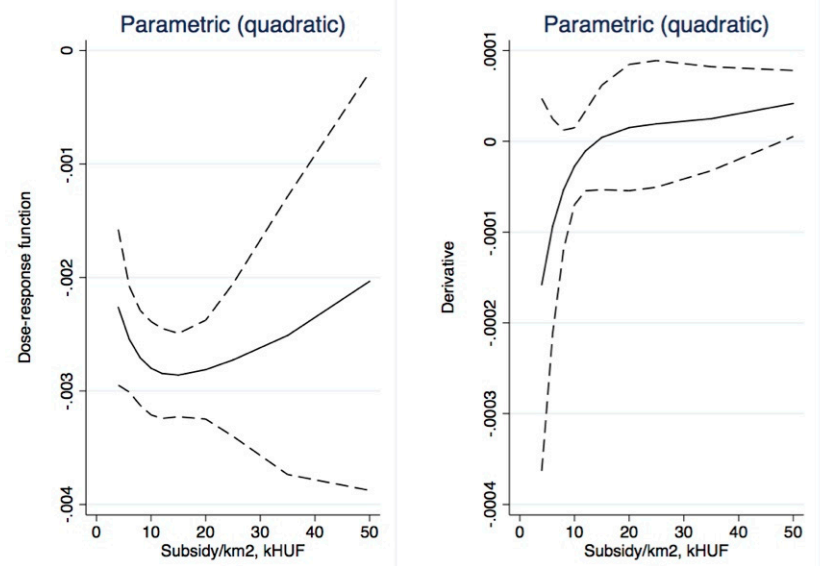

Figure 17. Parametric dose-response functions and average treatment effects with $95 \%$ confidence intervals (outcome is RDI, treatment is Subsidy per $\mathrm{km}^{2}$ ). Source: Own calculations using glmdose (Stata).
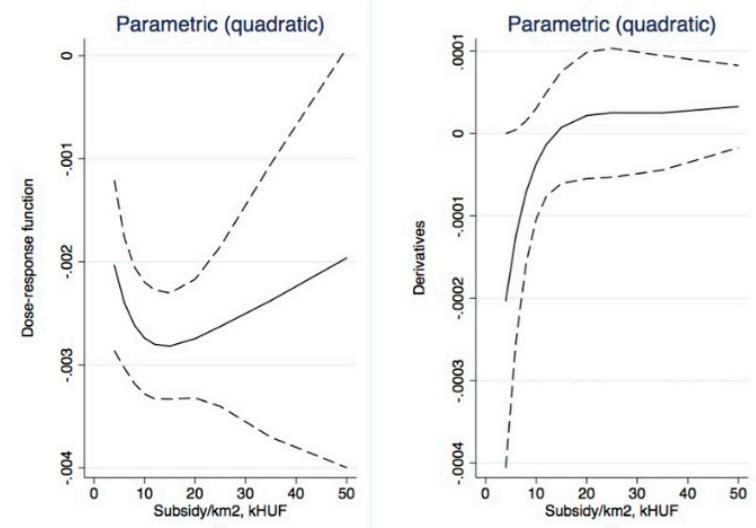

Figure 18. Parametric dose-response functions and average treatment effects with $95 \%$ confidence intervals (outcome is NMR, treatment is Subsidy per $\mathrm{km}^{2}$ ). Source: Own calculations using glmdose (Stata).

With non-parametric dose-response, we only found mild positive impacts for the subsidy per capita variable (Figure 9) for small (less than HUF 20,000) dosages. After these levels, the ATE quickly became insignificant. Somewhat more significant results were obtained with parametric approaches. Total subsidy (Figures 13 and 14) dose-response was significant for low treatment levels (less than HUF 300 million/region); similarly, ATE was first negative than insignificant. The ATE for subsidy per capita (Figures 15 and 16) was significant and negative for dosages smaller than HUF 50,000 and 20,000 , respectively. Overall, we conclude that no positive impact of the massive amount of subsidies absorbed by the regions may be identified.

\section{Discussion}

The main contribution to the literature of this paper is its assessment of (almost) an entire programming period and its focus on the overall effects of Rural Development payments at a highly disaggregated level using two development indicators, along with three definitions of subsidies. This analysis of subsidy data and econometric estimations for regions leads to several conclusions. First, we found considerable variation in the level of subsidies received by regions during the period under analysis. Second, and most importantly from a policy point of view, it was very difficult to identify any 
(positive) impact of European development subsidies, and not only because estimates were sensitive to the support variables that were selected. Only a few estimations revealed significant impacts, and these were almost exclusively negative instead of the expected positive. Due to the lack of relevant papers about this topic, especially those that focus on Central and Eastern European Countries, it is difficult to compare these results against those of other research to evaluate the impact of RDP. Some exceptions include research by Michalek [24], who assessed the impact of the SAPARD program in Slovakia, and the work of Bakucs et al. [23], who focused on the impact of RDPs on Hungarian regions in the period 2002-2008. Using directly comparable methodology, the authors of found negligible impacts for the programs on both Slovakian rural regions and Hungarian regions, respectively. We may additionally compare our results to the evaluations discussed in [21]. These also report minor, insignificant and sometimes negative impacts. However, [21] stressed that the quoted evaluations were done on "tiny samples" and "forced assumptions". None of these critiques applies for our case, due to the wealth of data provided by a six-year panel of 174 observations per year. We conclude that, irrespective of estimated coefficients, the impact of regional subsidies is negligible-a result that should raise important policy-related questions. Some possible explanations for this finding may be drawn from the literature. First, the LAU1 level of analysis may be either too small or too big to capture impact levels. For instance, [11] concluded that the impact of development policies is highly dependent on the geographical location of the treated region. Specifically, they found that rural areas close to city centers benefitted more from supporting policies than urbanized or sub-urbanized areas. We could not capture individual municipalities in our analysis. The other explanation is perhaps more detrimental for the medium-term development goals of Hungary. As [4] pointed out, if payments are not based on clear criteria, they may leave room for "political bargaining and side payments", thus sacrificing economic effectiveness for political goals-a situation that may certainly apply to the Hungarian case. [59] employed a comprehensive database of both accepted and rejected EU Structural and Cohesion Fund applications in Hungary. Covering almost the entire period we also investigated (2005-2012), they analyzed the types of grants susceptible to political favoritism. They concluded that potential incidences of favoritism are clearly present and these negatively impact the effectiveness of EU transfers. For instance, the authors found a large effect when subsidy applicants are public entities or projects are highly visible to the electorate (grants amounts were $16-21 \%$ higher than average). While these conclusions clearly underline our results, we feel that further research is needed to explore the impacts and mechanisms of subsidies in Hungary.

\section{Conclusions}

This study used highly disaggregated datasets to analyze the impact of all measures within the EU RDP on Hungarian LAU1 regions. Our analysis covered the 2008-2013 period, using a simple, net migration-based Quality of Life index, and a complex synthetic Rural Development Index-the latter estimated using a Spatial Durbin Panel Model building on a wealth of locality level indicators. To minimize bias, we used several impact assessment methods, namely the binary treatment effects based PSM-DID along with non-parametric and parametric GPS matching. While the binary PSM has limitations (especially the subjectivity of defining treated and non-treated regions, since all received some support), the GPS should solve this issue.

To answer the question posed in the title of this paper: our results fail to reveal any success of RDP in Hungary. It seems taxpayer's money would be spent more efficiently in other sectors-at least when the current RDP framework is considered. This paper adds to the ambiguities of the literature, as summarized by Bouayad-Agha et al. [2]: "while some authors do find evidence of a positive impact of Structural Funds on economic growth, others find little to no impact at all." However, considering the state-of-the-art methods we used-that we believe substantiate our results-alongside with the "political bargaining" phenomena and corruption experienced in Hungary, we are inclined to conclude the complete inefficiency of the use of EU RDP funds, forecasting rather gloomy perspectives for Hungarian small regions. 
We see two possible directions for future research. The first is to analyze the fund absorption capacity of regions, similar to the paper of Becker et al. [7]. Although the quality of local institutions would be hard to assess at such a disaggregated level, the human capital (perhaps proxied by level of education) of regions could explain the absorption capacity and consequently the low impact of EU RDP funds. Second, one could use text mining techniques to analyze the hundreds of thousands of individual projects funded in a programming period from EU RDP funds. This could reveal interesting allocation issues alongside with "notorious beneficiaries".

Author Contributions: Z.B. conceived and prepared this research, did the empirical estimations and wrote the Results and Discussion Sections. I.F. performed the review of evaluations and supervised the methodology. Z.B. worked on the Introduction Section and reviewed the final manuscript.

Funding: Zoltán Bakucs gratefully acknowledges support from Hungarian Scientific Research Fund (project no. 120080 "Impact of Rural Development Policy in Hungary. A Complex View")—Országos Tudományos Kutatási Alapprogramok. Zsófia Benedek gratefully acknowledges support from Global Development Network-CERGE-EI (project “Success or Waste of Taxpayers' Money? Impact of EU Rural Development Policies upon Hungarian NUTS3 Regions").

Conflicts of Interest: The authors declare no conflict of interest.

\section{Appendix A}

Table A1. Yearly correlation between RDI and NMR variables.

\begin{tabular}{lll}
\hline Year & & NMR \\
\hline 2008 & RDI & 0.882 \\
2009 & RDI & 0.907 \\
2010 & RDI & 0.825 \\
2011 & RDI & 0.744 \\
2012 & RDI & 0.696 \\
2013 & RDI & 0.803 \\
\hline
\end{tabular}

Source: Authors' calculations.
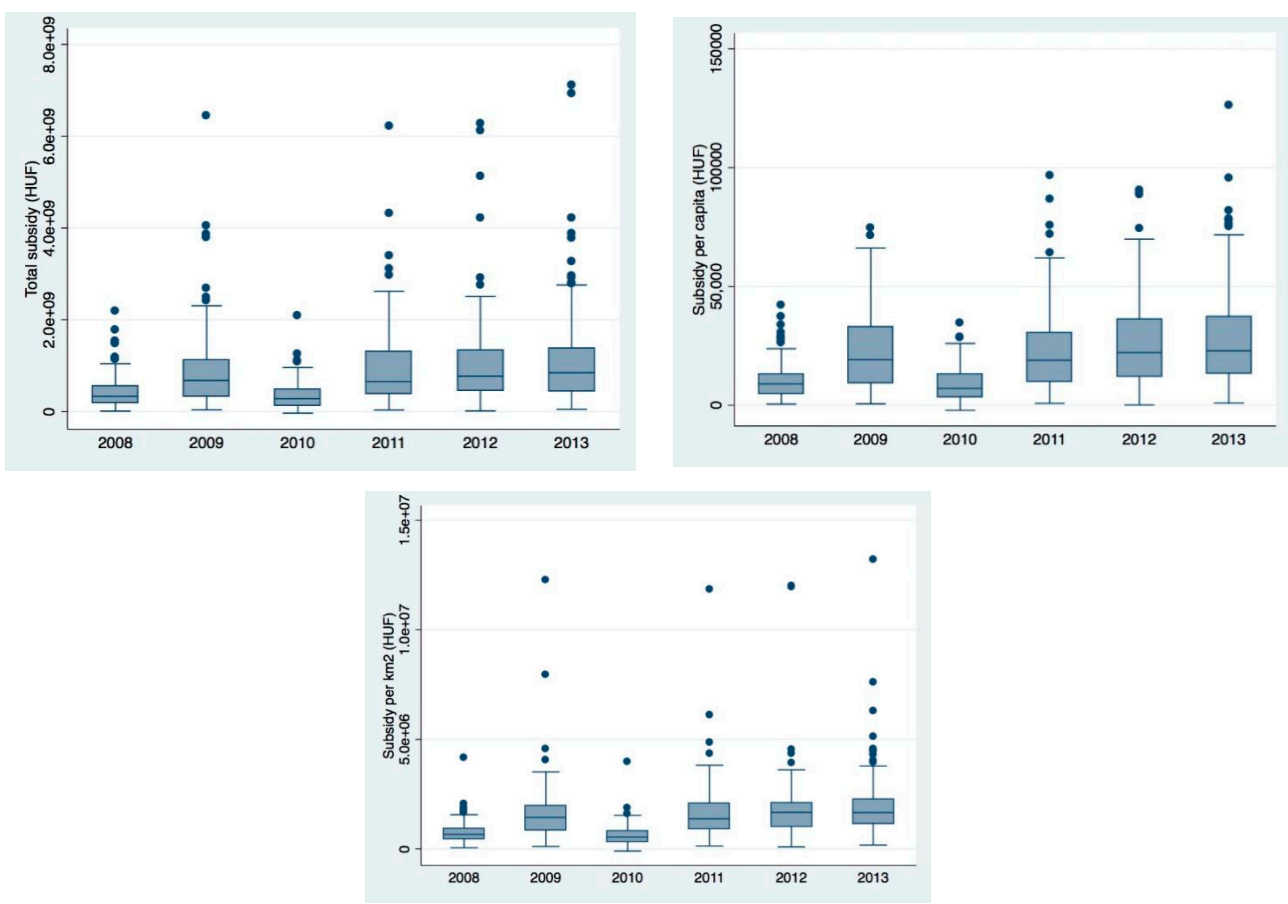

Figure A1. Boxplot of yearly subsidies received (total, per capita and per $\mathrm{km}^{2}$ ) (Hungarian Forints). Source: Own calculations. 

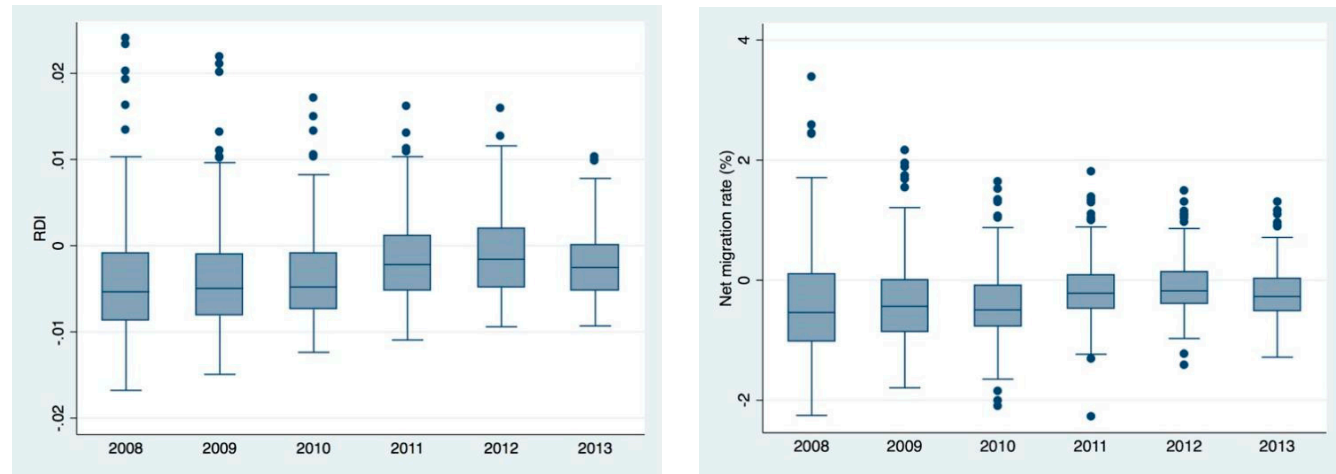

Figure A2. Boxplot of yearly RDI and NMR indices. Source: Own calculations.
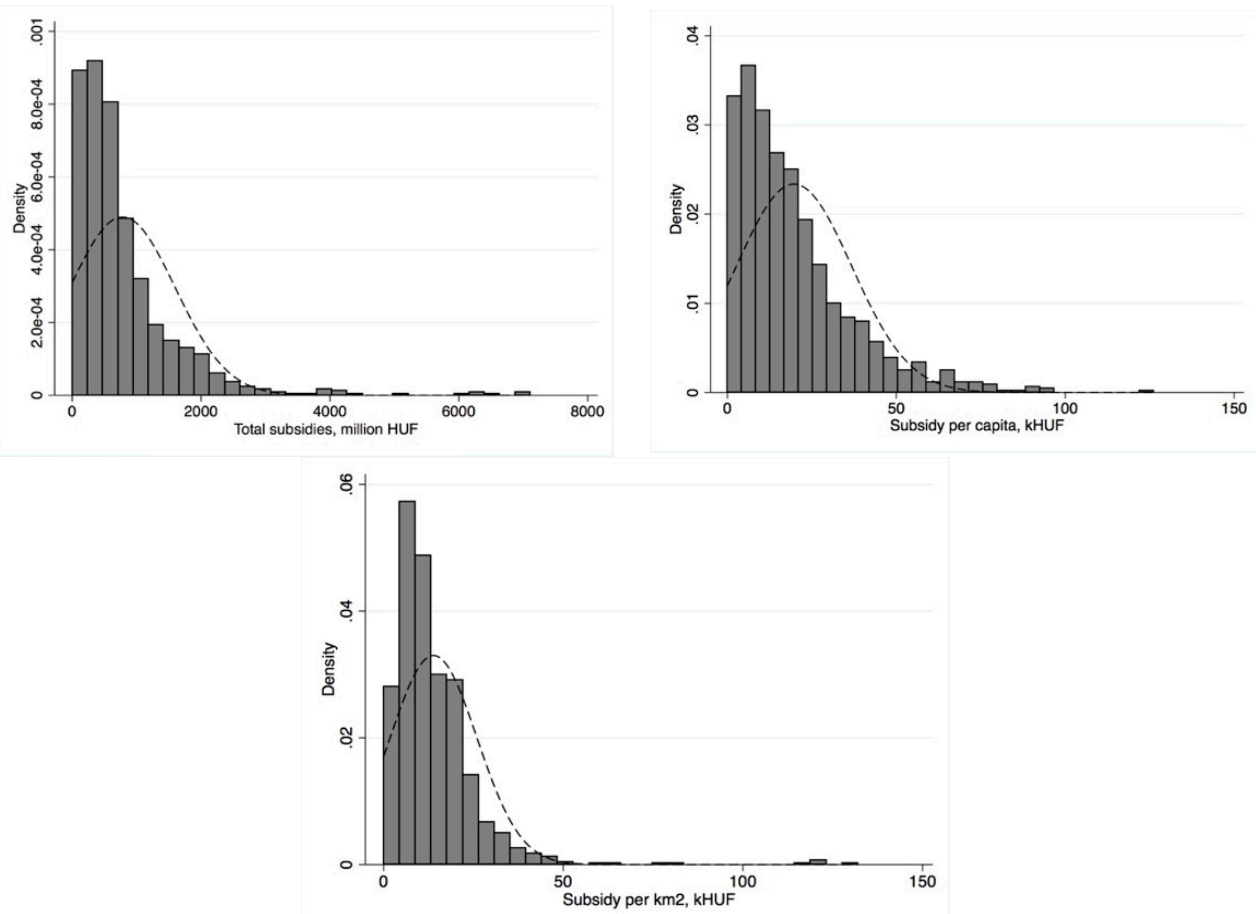

Figure A3. Histogram of total, per capita and per $\mathrm{km}^{2}$ subsidies, along with normal density (dashed line). Source: Own calculations.

\section{References}

1. Bourdin, S. Does the Cohesion Policy Have the Same Influence on Growth Everywhere? A Geographically Weighted Regression Approach in Central and Eastern Europe. Econ. Geogr. 2018, 1-32. [CrossRef]

2. Bouayad-Agha, S.; Turpin, N.; Védrine, L. Fostering the development of European regions: A spatial dynamic panel data analysis of the impact of cohesion policy. Reg. Stud. 2013, 47, 1573-1593. [CrossRef]

3. RodrÍguez-Pose, A.; Fratesi, U. Between development and social policies: the impact of European Structural Funds in Objective 1 regions. Reg. Stud. 2004, 38, 97-113. [CrossRef]

4. Mohl, P.; Hagen, T. Do EU structural funds promote regional growth? New evidence from various panel data approaches. Reg. Sci. Econ. 2010, 40, 353-365. [CrossRef]

5. Becker, S.O.; Egger, P.H.; Von Ehrlich, M. Going NUTS: The effect of EU Structural Funds on regional performance. J. Public Econ. 2010, 94, 578-590. [CrossRef]

6. Becker, S.O.; Egger, P.H.; Von Ehrlich, M. Too much of a good thing? On the growth effects of the EU's regional policy. Eur. Econ. Rev. 2012, 56, 648-668. [CrossRef] 
7. Becker, S.O.; Egger, P.H.; Von Ehrlich, M. Absorptive capacity and the growth and investment effects of regional transfers: A regression discontinuity design with heterogeneous treatment effects. Am. Econ. J. Econ. Policy 2013, 5, 29-77. [CrossRef]

8. Cerqua, A.; Pellegrini, G. Are we spending too much to grow? The case of Structural Funds. J. Reg. Sci. 2018, 58, 535-563. [CrossRef]

9. Becker, S.O.; Egger, P.H.; von Ehrlich, M. Effects of EU Regional Policy: 1989-2013. Reg. Sci. Urban Econ. 2018, 69, 143-152. [CrossRef]

10. Giua, M. Spatial discontinuity for the impact assessment of the EU regional policy: The case of Italian objective 1 regions. J. Reg. Sci. 2017, 57, 109-131. [CrossRef]

11. Gagliardi, L.; Percoco, M. The impact of European Cohesion Policy in urban and rural regions. Reg. Stud. 2017, 51, 857-868. [CrossRef]

12. Caldas, P.; Dollery, B.; Marques, R.C. European Cohesion Policy impact on development and convergence: A local empirical analysis in Portugal between 2000 and 2014. Eur. Plan. Stud. 2018, 26, 1081-1098. [CrossRef]

13. Fiaschi, D.; Lavezzi, A.M.; Parenti, A. Does EU cohesion policy work? Theory and evidence. J. Reg. Sci. 2018, 58, 386-423. [CrossRef]

14. Medeiros, E. Assessing territorial impacts of the EU Cohesion Policy: The Portuguese case. Eur. Plan. Stud. 2014, 22, 1960-1988. [CrossRef]

15. Michalek, J.; Zarnekow, N. Application of the rural development index to analysis of rural regions in Poland and Slovakia. Soc. Indic. Res. 2012, 105, 1-37. [CrossRef]

16. Spicka, J.; Naglova, Z.; Gurtler, M. Effects of the investment support in the Czech meat processing industry. Agric. Econ. Zemed. Ekon. 2017, 63, 356-369. [CrossRef]

17. Gustafsson, A.; Stephan, A.; Hallman, A.; Karlsson, N. The "sugar rush" from innovation subsidies: a robust political economy perspective. Empirica 2016, 43, 729-756. [CrossRef]

18. Brachert, M.; Dettmann, E.; Titze, M. Public Investment Subsidies and Firm Performance-Evidence from Germany. Jahrbücher Für Natl. Stat. 2018, 238, 103-124. [CrossRef]

19. Bachtrögler, J.; Hammer, C.; Reuter, W.H.; Schwendinger, F. Guide to the galaxy of EU regional funds recipients: Evidence from new data. Empirica 2019, 46, 103-150. [CrossRef]

20. Dall'Erba, S.; Fang, F. Meta-analysis of the impact of European Union Structural Funds on regional growth. Reg. Stud. 2017, 51, 822-832. [CrossRef]

21. Castaño, J.; Blanco, M.; Martinez, P. Reviewing Counterfactual Analyses to Assess Impacts of EU Rural Development Programmes: What Lessons Can Be Learned from the 2007-2013 Ex-Post Evaluations? Sustainability 2019, 11, 1105. [CrossRef]

22. Terluin, I.J.; Roza, P. Evaluation Methods for Rural Development Policy; LEI Wageningen UR: Wageningen, Netherlands, 2010.

23. Bakucs, Z.; Fertő, I.; Varga, Á.; Benedek, Z. Impact of European Union development subsidies on Hungarian regions. Eur. Plan. Stud. 2018, 26, 1121-1136. [CrossRef]

24. Michalek, J. Counterfactual Impact Evaluation of EU Rural Development Programmes-Propensity Score Matching Methodology Applied to Selected EU Member States. Volume 2: A Regional Approach; Joint Research Centre (Seville site): Seville, Spain, 2012.

25. Bia, M.; Mattei, A. Assessing the effect of the amount of financial aids to Piedmont firms using the generalized propensity score. Stat. Methods Appl. 2012, 21, 485-516. [CrossRef]

26. D'Attoma, I.; Pacei, S. Evaluating the Effects of Product Innovation on the Performance of European Firms by Using the Generalised Propensity Score. Ger. Econ. Rev. 2018, 19, 94-112. [CrossRef]

27. Michalek, J.; Ciaian, P. Capitalization of the single payment scheme into land value: generalized propensity score evidence from the European Union. Land Econ. 2014, 90, 260-289. [CrossRef]

28. Esposti, R. The empirics of decoupling: Alternative estimation approaches of the farm-level production response. Eur. Rev. Agric. Econ. 2017, 44, 499-537. [CrossRef]

29. Batory, A. 10. Corruption in East Central Europe: has EU membership helped? Handb. Geogr. Corrupt. 2018, 169. [CrossRef]

30. Fazekas, M.; Tóth, I.J. From corruption to state capture: A new analytical framework with empirical applications from Hungary. Political Res. Q. 2016, 69, 320-334. [CrossRef]

31. Tóth, I.J.; Hajdu, M. Competitive Intensity and Corruption Risks in the Hungarian Public Procurement 2009-2015; The Corruption Research Center: Budapest, Hungary, 2016. 
32. Tiebout, C.M. A pure theory of local expenditures. J. Econ. 1956, 64, 416-424. [CrossRef]

33. Liu, B.-C. Differential net migration rates and the quality of life. Rev. Econ. Stat. 1975, 57, 329. [CrossRef]

34. Michalos, A.C. Migration and the quality of life: A review essay. Soc. Indic. Res. 1996, 39, 121-166. [CrossRef]

35. Nakajima, K.; Tabuchi, T. Estimating interregional utility differentials. J. Reg. Sci. 2011, 51, 31-46. [CrossRef]

36. Faggian, A.; Corcoran, J.; Partridge, M. 22 interregional migration analysis. Handb. Res. Methods Appl. Econ. Geogr. 2015. [CrossRef]

37. Foley, M.; Angjellari-Dajci, F. Net migration determinants. J. Reg. Anal. Policy 2015, 45, 30.

38. Lukovics, M.; Kovács, P. Eljárás a területi versenyképesség mérésére. Területi Stat. 2008, 3, $245-263$.

39. Lukovics, M. Measuring regional disparities on competitiveness basis. In Regional Competitiveness, Innovation and Environment; JATE Press: Szeged, Hungary, 2009; pp. 39-53.

40. Douglas, S.; Wall, H.J. 'Voting with your feet'and the quality of life index: A simple non-parametric approach applied to Canada. Econ. Lett. 1993, 42, 229-236. [CrossRef]

41. Douglas, S.; Wall, H.J. Measuring Relative Quality of Life from a Cross-Migration Regression, with an Application to Canadian Provinces; Emerald Group Publishing Limited: Bingley, UK, 2000; Voloume 19, pp. 191-214.

42. Wirth, B. Ranking German regions using interregional migration. In School of Business and Economics at FAU Erlangen-Nuremberg Working Paper; Erlangen-Nuerenberg: Erlangen, Germany, 2013.

43. Baltagi, B. Econometric Analysis of Panel Data; John Wiley \& Sons: Hoboken, NJ, USA, 2008.

44. Cerulli, G. Econometric Evaluation of Socio-Economic Programs. Theory and Applications; Springer: Berlin/Heidelberg, Germany, 2015; Voloume 49, p. 308.

45. Rosenbaum, P.R.; Rubin, D.B. The central role of the propensity score in observational studies for causal effects. Biometrika 1983, 70, 41-55. [CrossRef]

46. Imbens, G.W.; Wooldridge, J.M. Recent developments in the econometrics of program evaluation. J. Econ. Lit. 2009, 47, 5-86. [CrossRef]

47. Guo, S.; Fraser, M.W. Propensity Score Analysis: Statistical Methods and Applications; SAGE Publications, Inc.: Thousand Oaks, CA, USA, 2010; Voloume 11.

48. Smith, J.A.; Todd, P.E. Does matching overcome LaLonde's critique of nonexperimental estimators? J. Econ. 2005, 125, 305-353. [CrossRef]

49. Gelman, A.; Meng, X.-L. Applied BAYESIAN Modeling and Causal Inference from Incomplete-Data Perspectives; John Wiley \& Sons: Hoboken, NJ, USA, 2004.

50. Bia, M.; Flores, C.A.; Flores-Lagunes, A.; Mattei, A. A Stata package for the application of semiparametric estimators of dose-response functions. Stata J. Promot. Commun. Stat. Stata 2014, 14, 580-604. [CrossRef]

51. Flores, C.A.; Flores-Lagunes, A.; Gonzalez, A.; Neumann, T.C. Estimating the effects of length of exposure to instruction in a training program: the case of job corps. Rev. Econ. Stat. 2012, 94, 153-171. [CrossRef]

52. Guardabascio, B.; Ventura, M. Estimating the dose-response function through a generalized linear model approach. Stata J. Promot. Commun. Stat. Stata 2014, 14, 141-158. [CrossRef]

53. Greene, W.H. Econometric Analysis, 5th ed.; Prentice Hall: Upper Saddle River, NJ, USA, 2000; p. 802.

54. Wooldridge, J.M. Econometric Analysis of Cross Section and Panel Data; MIT Press: Cambridge, MA, USA, 2010.

55. Drukker, D.M. Testing for serial correlation in linear panel-data models. Stata J. 2003, 3, 168-177. [CrossRef]

56. Elhorst, J.P. Spatial Econometrics: From Cross-Sectional Data to Spatial Panels; Springer: Berlin/Heidelberg, Germany, 2014; Volume 479.

57. Abadie, A.; Drukker, D.; Herr, J.L.; Imbens, G.W. Implementing matching estimators for average treatment effects in Stata. Stata J. 2004, 4, 290-311. [CrossRef]

58. Leuven, E.; Sianesi, B. Psmatch2: Stata Module to Perform Full Mahalanobis and Propensity Score Matching, Common Support Graphing, and Covariate Imbalance Testing; Statistical Software Components: Boston, MA, USA, 2018.

59. Muraközy, B.; Telegdy, Á. Political incentives and state subsidy allocation: Evidence from Hungarian municipalities. Eur. Econ. Rev. 2016, 89, 324-344. [CrossRef]

(C) 2019 by the authors. Licensee MDPI, Basel, Switzerland. This article is an open access article distributed under the terms and conditions of the Creative Commons Attribution (CC BY) license (http:/ / creativecommons.org/licenses/by/4.0/). 